\title{
Orographic Effects of the Tibetan Plateau on the East Asian Summer Monsoon: An Energetic Perspective
}

\author{
JINQIANG CHEN AND SIMONA BORDONI \\ California Institute of Technology, Pasadena, California
}

(Manuscript received 12 August 2013, in final form 23 December 2013)

\begin{abstract}
This paper investigates the dynamical processes through which the Tibetan Plateau (TP) influences the East Asian summer monsoon (EASM) within the framework of the moist static energy (MSE) budget, using both observations and atmospheric general circulation model (AGCM) simulations. The focus is on the most prominent feature of the EASM, the so-called meiyu-baiu (MB), which is characterized by a well-defined, southwest-northeast elongated quasi-stationary rainfall band, spanning from eastern China to Japan and into the northwestern Pacific Ocean between mid-June and mid-July.

Observational analyses of the MSE budget of the MB front indicate that horizontal advection of moist enthalpy, and primarily of dry enthalpy, sustains the front in a region of otherwise negative net energy input into the atmospheric column. A decomposition of the horizontal dry enthalpy advection into mean, transient, and stationary eddy fluxes identifies the longitudinal thermal gradient due to zonal asymmetries and the meridional stationary eddy velocity as the most influential factors determining the pattern of horizontal moist enthalpy advection. Numerical simulations in which the TP is either retained or removed show that the TP influences the stationary enthalpy flux, and hence the MB front, primarily by changing the meridional stationary eddy velocity, with reinforced southerly wind over the MB region and northerly wind to its north. Changes in the longitudinal thermal gradient are mainly confined to the near downstream of the TP, with the resulting changes in zonal warm air advection having a lesser impact on the rainfall in the extended MB region.
\end{abstract}

\section{Introduction}

Monsoons are conventionally defined as summertime tropical circulations with seasonally reversing prevailing winds accompanied by alternating dry and wet seasons associated with zonally asymmetric heating (e.g., Webster 1987; Webster and Fasullo 2003; Trenberth et al. 2006) and exert a significant and far-reaching influence on the general circulation of the atmosphere, the global hydrological cycle, and the atmospheric energy transport (e.g., Dima and Wallace 2003; Rodwell and Hoskins 1996, 2001). The Asian monsoon, the largest monsoon system on Earth, plays a crucial role in the entire Eastern Hemisphere tropics, subtropics, and midlatitudes, and affects $60 \%$ of the world population (e.g., Wang 2006). The East Asian summer monsoon (EASM) is one important branch of the Asian monsoon. On the large scale, the EASM is primarily characterized by a quasi-stationary,

Corresponding author address: Jinqiang Chen, M.C.131-24, California Institute of Technology, 1200 E. California Blvd., Pasadena, CA 91125.

E-mail: jcchen@gps.caltech.edu southwest-northeast elongated rainfall band, spanning from China to Japan into the northwestern Pacific (Fig. 1a). This precipitation front brings the major rainy season, referred to as meiyu in China and baiu in Japan, ${ }^{1}$ in these densely populated and rapidly growing regions. Its large intraseasonal and interannual variability causes flooding, droughts, heat waves, and other consequent natural hazards, affecting millions of people's lives and resulting in huge economic losses (e.g., Gao and Yang 2009; Sampe and Xie 2010; Waliser 2006; Yang and Lau 2006).

The EASM is different from the Indian monsoon and other monsoon systems in that it is characterized by mixed tropical and midlatitude influences with frontal

\footnotetext{
${ }^{1}$ In China, the name meiyu is used for persistent rainfall from mid-June to mid-July over the Yangtze River Valley (Tao 1987). The name baiu is used in Japan during the same period (Saito 1985). In Chinese, mei means plums, which in the Yangtze River valley reach maturity in the meiyu-baiu season. A homonym of mei in Chinese means mold, which vividly describes the tendency to molding under very moist and warm atmospheric conditions.
} 

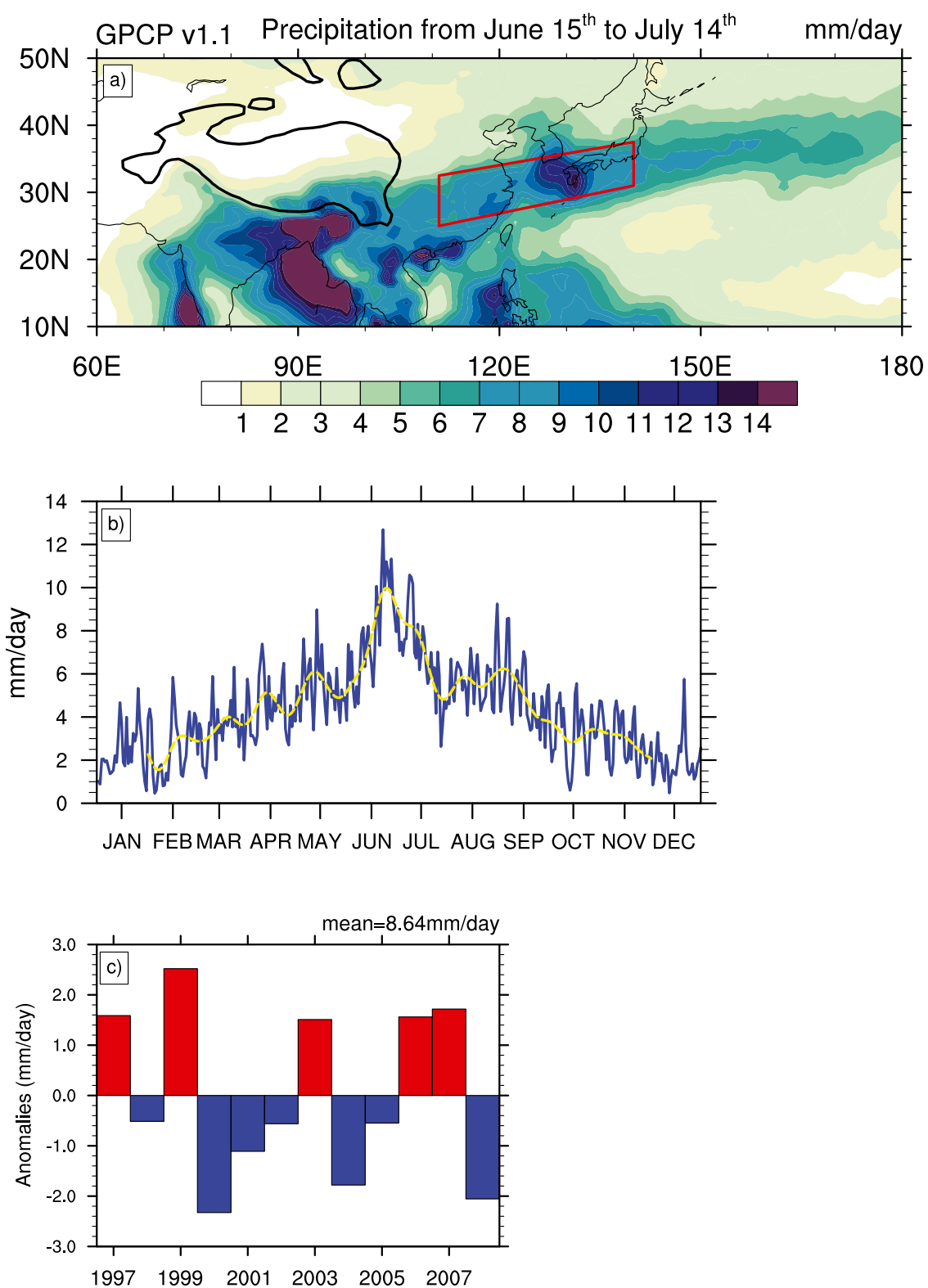

FIG. 1. Climatology of the MB season. (a) Climatological mean precipitation. (b) Seasonal cycle of the precipitation averaged over the area enclosed by the red lines in (a), where precipitation is the largest. The blue and yellow lines show the daily mean precipitation and filtered precipitation by a low-pass filter with a cutoff period of 20 days, respectively. The tick marks on the horizontal axis correspond to the middle of each month. (c) Interannual precipitation anomaly over the enclosed region. Thick black contour in (a) shows where orography intersects the 800-hPa level.

systems and jet stream effects (Ding and Chan 2005; Molnar et al. 2010). One of its notable features is its seasonal northward and northeastward migration remarked by three stationary periods, two abrupt northward jumps, and rapid southward retreat: heavy rainfall starts in the South China Sea (SCS) and tropical oceans at the beginning of May and shifts rapidly to the Yangtze
River Valley, the Korean peninsula, and southern Japan in mid-June, when the meiyu-baiu (MB) front reaches maturity; in mid-July, the rainfall core jumps to northern and northeast China, marking the end of the MB, then retreats back to South China at the end of August (e.g., Ding and Chan 2005; Gao et al. 2011; Sampe and Xie 2010). 
The formation of the EASM is believed to be the product of land-sea thermal contrast, orographic forcing, and the seasonal shift of the subtropical westerly jet. In simulations with idealized continental configuration, land-sea thermal contrast alone, because of the differing response of land and ocean surfaces to the seasonally varying insolation, was shown to produce a precipitation zone to the east of the continent and a dry zone to the west through Rossby wave dynamics and ventilation of low moist static energy (MSE) air from the ocean to the land, which resemble the large-scale summertime precipitation pattern over Eurasia (Chou et al. 2001). More comprehensive simulations, however, suggest that a realistic EASM can be simulated only when topography over Asia is included (e.g., Kitoh 2004; Liu and Yin 2002; Park et al. 2012; Wu et al. 2012). The Tibetan Plateau (TP) has long been held to exert a profound influence on the Asian climate primarily through thermal forcing (e.g., Flohn 1957; Yeh et al. 1957; Li and Yanai 1996). During the warm season, increased surface heat flux over the TP drives the large-scale atmospheric circulation and reinforces the land-sea thermal contrast, resulting in an intensified EASM (Wu et al. 1997, 2002, 2007, 2012): elevated heat flux causes cross-isentropic surface airflow along the TP slopes and results in cyclonic circulation around the TP in the lower troposphere and anticyclonic circulation [the so-called Tibetan or South Asian high (SAH)] in the upper troposphere (Yanai and $\mathrm{Wu}$ 2006). The lower-level cyclonic circulation strengthens the moisture transport to the EASM regions, thus reinforcing the precipitation. The establishment of SAH, one of the hallmarks of the largerscale Asian monsoon, has a significant impact on the seasonal transition of the atmospheric circulation over the EASM areas and far-reaching influences over the entire Northern Hemisphere (Enomoto et al. 2003; Yanai and Wu 2006; Rodwell and Hoskins 2001).

Recent work, however, suggests that mechanical effects might be more important than traditionally thought: the subtropical westerly jet, whose core is still located on the high-elevation terrain of the TP in late spring (Park et al. 2012), induces a region of lower-level downstream convergence, which might be a primary driver of the EASM [work of Takahashi and Battisti, reported by Molnar et al. (2010)]. This hypothesis might explain why the demise of the MB in mid-July is concurrent with the northward jump of the subtropical westerly jet (as already identified in late 1950s; e.g., Dao and Chen 1957; Suda and Asakura 1955), in spite of increasing land-sea thermal contrast. While suggestive, the precise workings of this mechanism on the formation of the MB rainband have not been fully investigated.
In a recent observational study, Sampe and Xie (2010) called for a reinterpretation of the thermal influence of the TP on the EASM. At the beginning of boreal summer, because of the elevated topography and latent heating due to monsoonal convection in South Asia, air over and south of the TP is warmer than the surrounding regions. The subtropical westerly jet that is still prevailing over the TP advects warm air from the southeastern TP to the MB region. The warm air advection provides a largescale environmental forcing capable of maintaining the MB rainfall band even in the absence of diabatic terms. Such forcing can also steer weather disturbances, which favor vertical convection by intensifying lower-level moisture advection with transient upward motion. As the jet stream rapidly jumps northward in mid-July (e.g., Schiemann et al. 2009), westerly flow and maximum midtropospheric temperatures are no longer colocated, causing the rapid weakening of the EASM rainfall band.

Despite being a large-scale feature of the summer tropical and subtropical circulation over eastern Asia and the northwestern Pacific, the EASM is not well represented in most general circulation models (GCMs), both in terms of its climatological features and seasonal evolution (Sampe and Xie 2010). Model resolution is found to be a factor affecting the quality of the simulated large-scale precipitation over the EASM region (Solomon et al. 2007). Ocean-atmosphere interactions are other factors believed to produce significantly different simulated precipitation in the Asian monsoon: the intensity of the EASM is relatively lower in atmospheric GCMS (AGCMs) in which sea surface temperatures (SSTs) are prescribed, and no interaction between atmosphere and ocean is allowed (Gao et al. 2011; Kitoh 2004).

Because of the socioeconomic importance of the EASM, its meteorological and climatological significance are highlighted and widely investigated in the literature (e.g., Ding and Chan 2005; Wang 2006). However, even its large-scale dynamics, let alone factors controlling its multiscale variability, remains poorly understood. Fundamental questions, such as what controls the location and the seasonal evolution of the EASM front, or why maximum rainfall is not colocated with maximum SSTs, remain largely unanswered. Finding answers to these questions is even more pressing in the face of the predicted expansion of subtropical dry zones with climate change, with potentially significant impacts on subtropical precipitation fronts such as the EASM, and enhanced regional sensitivity to greenhouse gases and aerosol radiative forcing (e.g., Hirahara et al. 2012; Hsu et al. 2013). In this paper, we attempt to address some of these questions, and we specifically focus on the mechanisms through which the TP affects the formation and seasonality of the EASM. This paper follows the same 
spirit of Sampe and Xie (2010), but we frame our analysis within the more general context of the MSE and moisture budgets. In section 2, we briefly describe the data and model used in this study. In section 3, we summarize the MB climatology from a larger-scale perspective. In section 4, we discuss the observed MSE and moisture budgets, which are decomposed into mean and eddy contributions. The hypotheses emerging from the observations are further tested in section 5, where we use GCM simulations in which the TP is either retained or removed. Summary and discussion follow in section 6 .

\section{Data and model description}

Precipitation data are from the Global Precipitation Climatology Project (GPCP) $1^{\circ}$ Daily Precipitation Dataset (1DD) plotted over a $1^{\circ} \times 1^{\circ}$ latitude-longitude grid from 1997 to 2008 with daily temporal resolution (Huffman et al. 2001). All other data are from the European Centre for Medium-Range Weather Forecasts (ECMWF) Interim Re-Analysis (ERA-Interim) products, spanning the 20-yr period from 1990 to 2009. Surface fluxes (latent heat and sensible heat) and radiation fluxes are from ERA-Interim (1.5 grid; Dee et al. 2011) 3-h-forecast fields produced from forecasts beginning at 0000 and 1200 UTC. Data on pressure levels, such as temperature, wind field, and humidity, are obtained from ERAInterim ( 37 pressure levels, $512 \times 256$ N128 Gaussian grid, analysis fields produced for 0000, 0600, 1200, and 1800 UTC) in the Data Support Section of the National Center for Atmospheric Research (NCAR). The energy and radiation flux data are then converted to daily data, while data on pressure levels are analyzed at a four times daily frequency to improve eddy statistics.

We use the reanalysis data to compute the MSE and moisture budgets for the EASM, and we perform a decomposition of all terms in the budgets into mean, and stationary and transient eddy components. To do so, we conventionally denote $(\cdot)^{\prime}$ as the deviation from the monthly time mean $\overline{(\cdot)}$ for each individual year (e.g., $u^{\prime}=u-\bar{u}$ ), and $(\cdot)^{*}$ as the deviation from the global zonal mean [.] (e.g., $u^{*}=u-[u]$ ). As detailed in Eq. (6), we thus decompose fluxes into mean, stationary, and transient eddy terms. Monthly total and eddy fluxes are computed for each year and then averaged over all available years to generate a 20-yr long-term climatology. Based on the above definitions, transient eddies contain submonthly synoptic-scale variability, with longerscale variability being captured by the stationary eddy terms.

Numerical simulations are performed with the atmospheric component of the Geophysical Fluid Dynamics Laboratory (GFDL) Atmospheric Model, version 2.1
(AM2.1; Anderson et al. 2004). AM2.1 uses a finitevolume dynamical core (Lin 2004) with $2.5^{\circ} \times 2.0^{\circ}$ horizontal resolution and 24 vertical levels. Climatologically fixed SSTs from monthly mean Reynolds SST analysis are used as boundary condition (Smith et al. 1996). Two different model integrations are performed with different topography over Asia, one where full topography at present-day height is retained (control) and one where the TP and the Himalaya mountains are removed (experiment). More specifically, in the no-TP experiment, the entire TP and Central Asian mountains from $45^{\circ}$ to $125^{\circ} \mathrm{E}$ and from $28^{\circ}$ to $55^{\circ} \mathrm{N}$ are reduced by $95 \%$. The experiments are the same as those described in Park et al. (2012). Climatological mean winds, temperature, and geopotential height fields obtained from the control run are used as initial conditions in the experiment run. Each experiment ran for 19 years, and the last 12 years of the simulations are used for the analysis.

Previous studies have shown that the presence of the TP causes changes in the SSTs in the surrounding oceanic regions, which have an impact on the evolution of the EASM in addition to the direct effects from the TP (Abe et al. 2004; Kitoh 2004). However, in this paper, we focus on the direct effects of the TP on the EASM and leave examination of possible indirect effects through SST changes to future studies.

\section{Meiyu-baiu climatology}

Following Sampe and Xie (2010), we define 15 June14 July, 16 May-14 June, and 15 July-13 August as the climatological MB, pre-MB, and post-MB seasons, respectively. During the MB season, a spatially wellorganized rainfall band extends over East Asia and the northwestern Pacific (Fig. 1a). The time evolution of the daily precipitation averaged over the $\mathrm{MB}$ region (Fig. 1b) shows a gradual increase from winter to late spring, and a sharp increase in mid-June, when the precipitation reaches its peak; around mid-July, the precipitation decreases rapidly and returns to values comparable to those in the pre-MB season. The MB also shows a large interannual variability in its duration and intensity which causes variations up to $20 \%$ ( $1 \sigma$ variability) in precipitation during the MB season (Fig. 1c), far larger than that in the Indian summer monsoon (e.g., Krishnan et al. 2011).

The climatological conditions of the MB have been described at length in the literature (e.g., Ding and Chan 2005; Ninomiya and Murakami 1987; Sampe and Xie 2010) and here we only provide a brief summary. Generally speaking, the MB rainfall is associated with pronounced lower-level moisture flux convergence (Fig. 2a) and wind convergence (Fig. 2c). A large meridional gradient of specific humidity (Fig. 2a) is present in both 

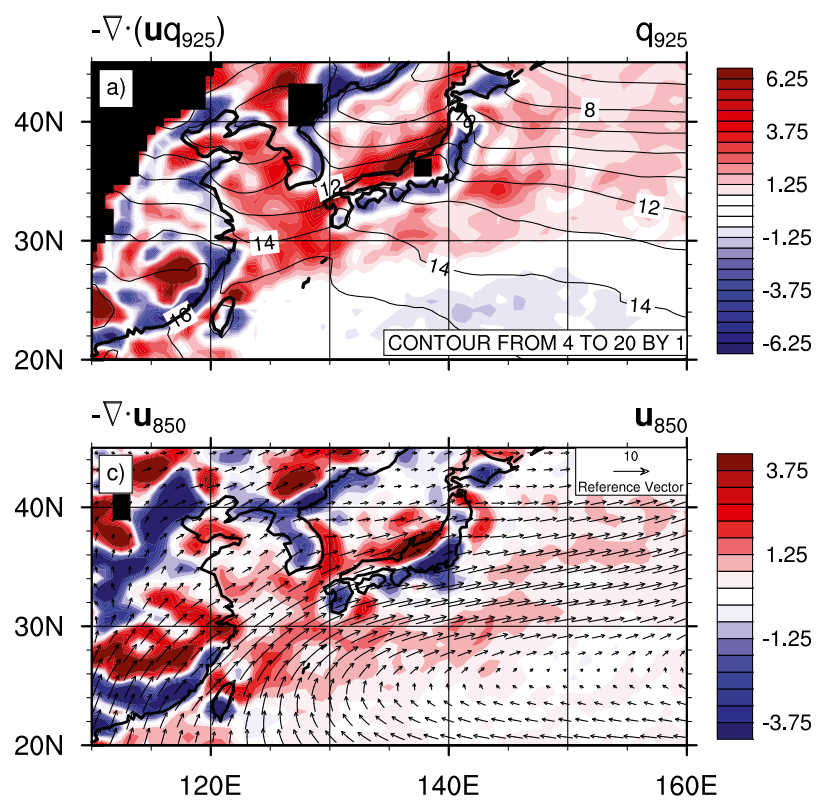
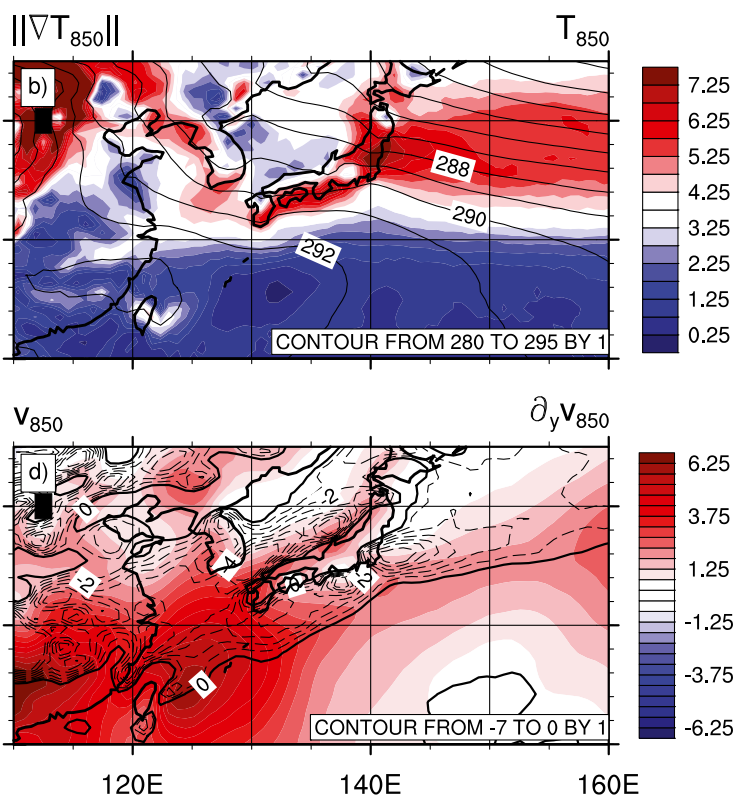

FIG. 2. The MB climatology. (a) Moisture flux convergence (color shading, $\mathrm{g} \mathrm{kg}^{-1} \mathrm{day}^{-1}$ ) and near-surface ( $925 \mathrm{hPa}$ ) specific humidity (contours, $\left.\mathrm{g} \mathrm{kg}^{-1}\right)$. (b) Absolute value of lower-level $(850 \mathrm{hPa})$ temperature gradient [color shading $\mathrm{K}(1000 \mathrm{~km})^{-1}$ ] and temperature (contours, K). (c) Lower-level $(850 \mathrm{hPa})$ wind convergence (color shading, $10^{6} \mathrm{~s}^{-1}$ ) and wind field (vectors, $\mathrm{m} \mathrm{s}^{-1}$ ). (d) Lower-level $(850 \mathrm{hPa})$ meridional wind (color shading, $\left.\mathrm{m} \mathrm{s}^{-1}\right)$ and meridional divergence [contours, $\mathrm{m} \mathrm{s}^{-1}(1000 \mathrm{~km})^{-1}$ ].

the meiyu and the baiu regions but a sharp meridional gradient of temperature (Fig. 2b) is only seen in the baiu region and farther downstream over the northwestern Pacific, which confirms that only the baiu is associated with a lower-level baroclinic zone (e.g., Chen and Chang 1980; Ding 1992; Ding and Chan 2005). The importance of the zonal wind (i.e., the subtropical westerly jet) in the maintenance of the rainband has been strongly emphasized in the literature (e.g., Molnar et al. 2010; Sampe and Xie 2010), while the role of the meridional wind has primarily been interpreted in association with the southerly moisture transport from tropical oceans. Here, we will argue for a more fundamental role of the meridional wind as an intrinsic component of the circulation response to the TP forcings and an essential element of the MB front. As is evident in Fig. 2d, over the MB region the meridional wind is primarily from the south, advecting warm and moist air from the tropical oceans to support the MB rainfall band. The meridional wind convergence contributes significantly to the total horizontal convergence (Fig. 2c); in fact, the zonal winds diverge in the MB region primarily due to the interaction of the zonal wind and the TP.

\section{Position of the meiyu-baiu}

\section{a. Temperature advection}

Sampe and Xie (2010) investigated the large-scale dynamics of the MB in the context of the dry thermodynamic budget evaluated from the Japanese 25-year Reanalysis
Project (JRA-25) and argued that temperature advection from the southeastern flank of the TP at $500 \mathrm{hPa}$ is important in inducing vertical motion and positioning the MB front. The dry thermodynamic equation in pressure coordinates ${ }^{2}$ is

$$
\overline{\partial_{t} T}=\bar{Q} / c_{p}-\frac{\bar{\omega}}{c_{p}} \overline{\partial_{p} s}-\overline{\mathbf{v}} \cdot \nabla_{p} \bar{T}-\frac{1}{c_{p}} \overline{\omega^{\prime} \partial_{p} s^{\prime}}-\overline{\mathbf{v}^{\prime} \cdot \nabla_{p} T^{\prime}},
$$

where $Q$ is diabatic heating-cooling, $c_{p}$ is the specific heat at constant pressure, $s=c_{p} T+g z$ is the dry static energy, $\mathbf{v}$ is horizontal wind, $\omega$ is the vertical pressure velocity, $T$ is temperature, $z$ is geopotential height, and $g$ is gravitational acceleration. Here $(\cdot)^{\prime}$ denotes time deviations from the temporal mean $\overline{(\cdot)}$. Averaged over a climatological period, the heat storage on the left-hand side can be neglected. Here we briefly discuss the thermodynamic budget in the MB region based on ERAInterim data and compare our most important findings with those in Sampe and Xie (2010).

In the tropics, the leading-order balance is between the vertical advection term [second term on the right-hand side in Eq. (1)] and the diabatic term, with smaller

\footnotetext{
${ }^{2}$ Sampe and Xie (2010) write the thermodynamic equation in potential temperature. Here we use temperature for notation consistency with Eq. (2), used to derive the moist static energy budget.
} 

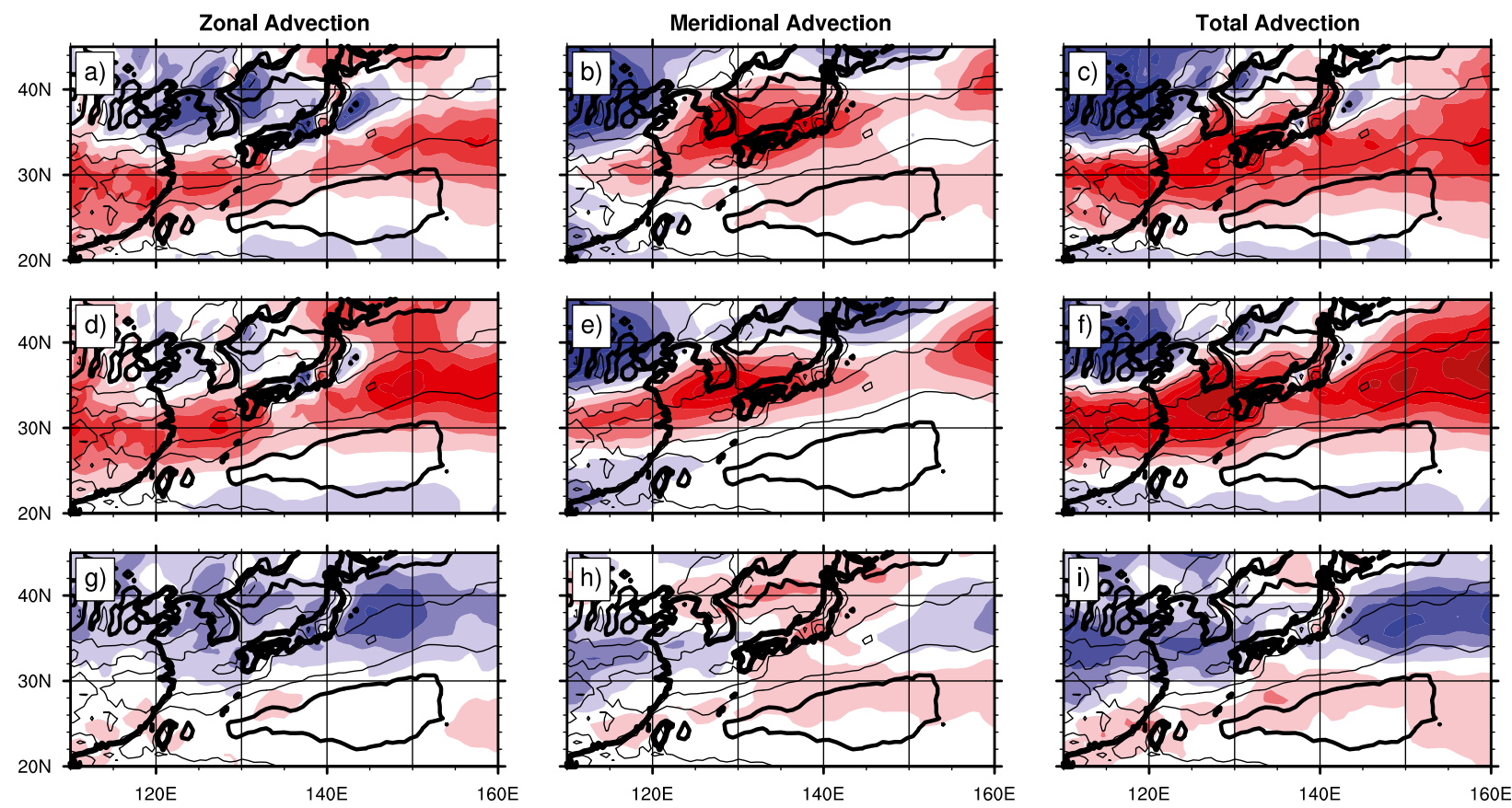

CONTOUR FROM -.06 TO .06 BY .02

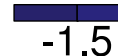

\section{$-0.5$}

0.5

1.5

FIG. 3. Midtropospheric temperature advection in the MB season. (left) Zonal, (center) meridional, and (right) total horizontal temperature advection. The (top) total advection, (middle) mean advection, and (bottom) transient eddy term. In all panels, color shading indicates temperature advection $\left[\mathrm{K} \mathrm{day}^{-1}\right.$, with warm (cold) colors indicating warm (cold) air advection] and contours are the midtropospheric vertical velocity $\left[\mathrm{Pa} \mathrm{s}^{-1}\right.$, with upward (downward) motion in solid (dashed) contours and the zero contour thickened].

contributions from the horizontal temperature advection (the third term on the right-hand side) because of weak temperature gradients (e.g., Sobel et al. 2001). However, in the MB region, especially over the baiu region and the northwestern Pacific, horizontal advection becomes significant and provides warm air advection that well correlates with the vertical ascending motion (Figs. 3c,f; Sampe and Xie 2010). Both zonal and meridional components contribute to the overall pattern of warm air advection in the MB region, with the former dominating in the meiyu region and the northwestern Pacific at lower latitudes (Figs. 3a,d), and the latter dominating in the baiu region and the northwestern Pacific at higher latitudes (Figs. 3b,e). In partial agreement with Sampe and Xie (2010), we find that transient eddy fluxes are negligible in limited areas of the MB region but become more important farther downstream over oceanic regions (Fig. 3i).

While the midtropospheric dry thermodynamic balance successfully explains the overall position of the MB rainfall band, it has the conceptual disadvantage of treating the diabatic term as a known forcing, which in fact influences and strongly depends on the circulation itself. Even when used as a diagnostic tool from reanalysis data, it provides the challenge of estimating the not readily available diabatic term as the residual of the thermodynamic budget, with results potentially dependent on the relatively coarse vertical resolution.

\section{b. Moist static energy balance}

Previous work has emphasized the advantages of the MSE budget over the dry thermodynamic equation in studies of tropical-subtropical circulations in which comprehensive effects of temperature, humidity, and diabatic processes are taken into consideration, and the interaction between moist convection and the circulation is accounted for (e.g., Chou and Neelin 2003; Neelin 2007). Following these studies, first we consider the vertically integrated thermodynamic and moisture equations in pressure coordinates,

$c_{p}\left\langle\partial_{t} T\right\rangle+c_{p}\langle\mathbf{v} \cdot \nabla T\rangle+\left\langle\omega \partial_{p} s\right\rangle=\left\langle Q_{c}\right\rangle+S^{\text {net }}+R^{\text {net }}+\mathrm{SH}$ 

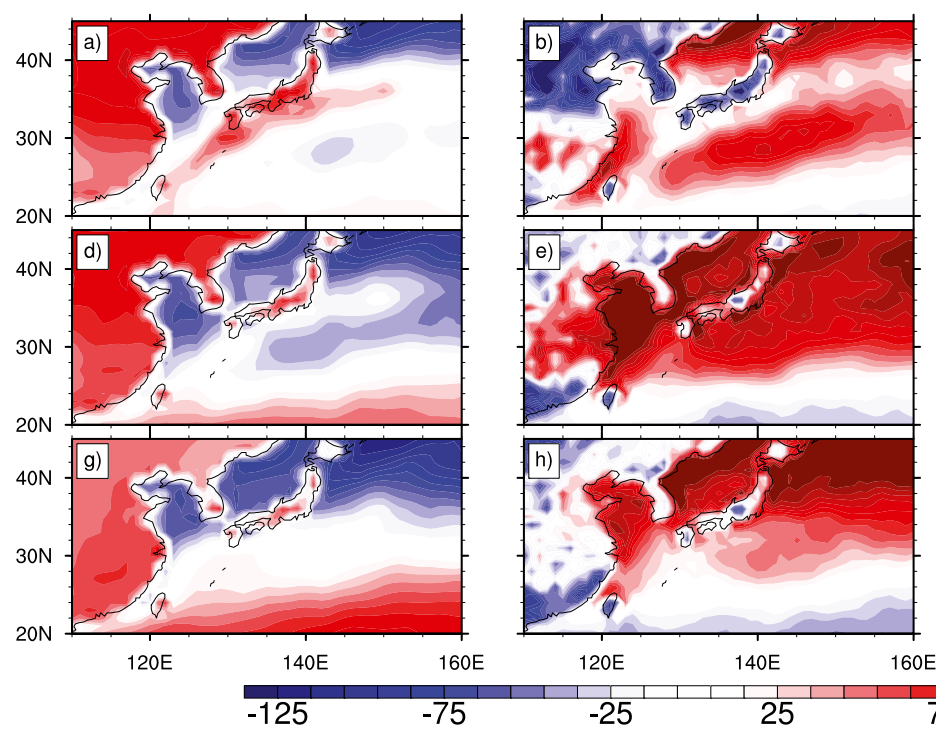
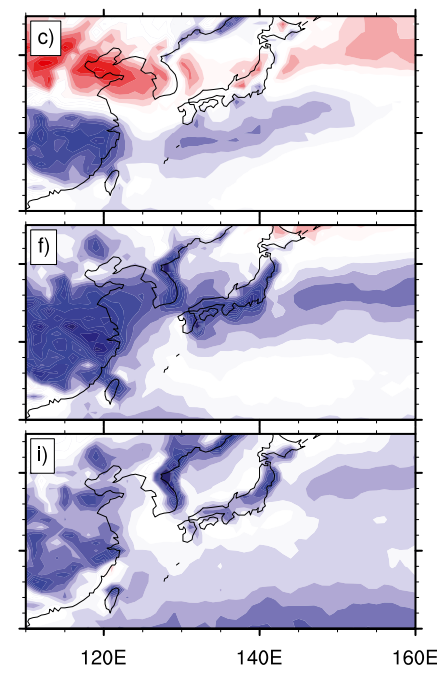

125

FIG. 4. Vertically integrated MSE budget. (left) Net energy flux into the atmospheric column $\overline{F^{\text {net }}}$, (center) vertical integral of horizontal moist enthalpy advection $-\langle\overline{\mathbf{v} \cdot \nabla E}\rangle$, and (right) vertical integral of vertical MSE advection $-\langle\overline{\omega \partial h / \partial p}\rangle$ for the (top) pre-MB, (middle) MB, and (bottom) post-MB seasons. (Color shading is in $\mathrm{W} \mathrm{m}^{-2}$.)

$L_{v}\left\langle\partial_{t} q\right\rangle+L_{v}\langle\mathbf{v} \cdot \nabla q\rangle+L_{v}\left\langle\omega \partial_{p} q\right\rangle=\left\langle Q_{q}\right\rangle+\mathrm{LH}$,

where $q$ is specific humidity and $\langle\cdot\rangle$ indicates a vertical mass integral [i.e., $\int(\cdot) d p / g$ ]. The vertically integrated change of internal energy and work done by the atmosphere is balanced by the energy fluxes at the boundaries of the atmospheric column, that is, the net shortwave radiation $S^{\text {net }}$, the net longwave radiation $R^{\text {net }}$ and the sensible heat $\mathrm{SH}$, and the convective heating $Q_{c}$. The vertically integrated change of moisture in the atmospheric column is balanced by the evaporation $\mathrm{LH} / L_{v}$ and precipitation $-\left\langle Q_{q}\right\rangle / L_{v}$, where $\mathrm{LH}$ is the surface latent heat flux, $Q_{q}$ is moistening, and $L_{v}$ is latent heat of vaporization. The sum of convective heating and moistening must be zero in the atmospheric column because precipitation $P=-\left\langle Q_{q}\right\rangle / L_{v}=\left\langle Q_{c}\right\rangle / L_{v}$.

The MSE balance in the atmospheric column is obtained by summing Eqs. (2) and (3) and averaging over a climatological period:

$$
\left\langle\overline{\frac{\partial E}{\partial t}}\right\rangle=\overline{F^{\text {net }}}-\langle\overline{\mathbf{v} \cdot \nabla E}\rangle-\left\langle\overline{\omega \frac{\partial h}{\partial p}}\right\rangle,
$$

and

$F^{\mathrm{net}}=S_{t}^{\downarrow}-S_{t}^{\uparrow}-S_{s}^{\downarrow}+S_{s}^{\uparrow}-R_{t}^{\uparrow}+R_{s}^{\uparrow}-R_{s}^{\downarrow}+\mathrm{SH}+\mathrm{LH}$,

where $h=c_{p} T+g z+L_{v} q$ is the MSE, $E=c_{p} T+L_{v} q$ is the atmospheric moist enthalpy, and $F^{\text {net }}$ is the net energy flux into the atmosphere, with the subscript $t$ and $s$ denoting the top of atmosphere and surface, respectively. The vertical advection of MSE is the column-integrated product of vertical velocity in pressure coordinate $\omega$ and the MSE stratification $\partial_{p} h$, whose vertical integral in the troposphere is negative in pressure coordinates. Therefore, regions of positive vertical advection, where $\overline{\langle\omega \partial h / \partial p\rangle}>0$, correspond to ascending vertical motion, and vice versa. That is, vertical motion can be inferred from the sum of the net energy flux into the atmospheric column and horizontal advection of moist enthalpy, provided that the storage term is negligible over a climatological period. In the tropics and over land, the vertical MSE advection is almost entirely balanced by the net energy flux; however, over oceans outside of the deep tropics, the horizontal advection of moist enthalpy is nonnegligible and essential in maintaining vertical motions (Fig. 4). The horizontal moist enthalpy advection has also been shown to be critical in setting the poleward boundary of monsoonal convergence zones over subtropical continents (Chou and Neelin 2003; Neelin 2007). In the extratropics, where precipitation is primarily due to moisture transport along isentropes by large-scale baroclinic eddies, vertical motion is primarily along rather than across isentropes (which are parallel to isobars in the tropics), and the stratification (which determines the total gross moist stability) is dynamically determined (e.g., Schneider 2004), rather than thermodynamically constrained to follow a moist adiabat as it is in the tropics. Therefore the 
MSE budget in the extratropics provides weaker constraints on the circulation (e.g., Merlis and Schneider 2010). With these caveats in mind, the MSE budget as written in Eq. (4) does hold across latitudes and we will use it in the MB region to shed some light on its dynamics.

As discussed in previous studies (e.g., Chou and Neelin 2003), $\overline{F^{\text {net }}}$ is positive over land and most convective zones in tropical oceans but negative in extratropical oceans (Fig. 4, left). In boreal summer, the continents in the Northern Hemisphere receive high insolation extending all the way to high latitudes. The outgoing longwave radiation depends largely on the upper-tropospheric temperature and cannot fully compensate the incoming insolation. The thermal inertia of land is very small, which results in a zero heat flux condition at the surface (Chou and Neelin 2003), whereas, over the oceans, the net flux into the surface can be balanced by heat transport and heat storage, which in turn affects $\overline{F^{\text {net }}}$. As a result, $\overline{F^{\text {net }}}$ is positive over the Northern Hemisphere continents and convective oceanic regions in boreal summer. The horizontal advection of moist enthalpy tends to offset $\overline{F^{\text {net }}}$ in most regions (Fig. 4, center). Over land and convective tropical oceans, the horizontal moist enthalpy advection is negative, indicating that moist enthalpy is transported away from regions of positive $\overline{F^{\text {net}}}$; however, over nonconvective oceans and parts of the continents, the horizontal moist enthalpy advection is positive, indicating that moist enthalpy is transported into these regions of negative $\overline{F^{\text {net }}}$ from neighboring areas.

The vertical MSE advection in Fig. 4 (right) is obtained explicitly as the product of the MSE stratification, which is susceptible to the relatively coarse vertical resolution of the data used, and the vertical velocity. In our analysis, the MSE budget [Eq. (4)] does not close, resulting in a relatively small residual caused by insufficient vertical resolution, nonresolved subgrid-scale motions, and existing imbalances of atmospheric energy and mass in the reanalysis data from both the ERA-Interim forecast model and the assimilation system (Berrisford et al. 2011). In Fig. 5 (left) we show the vertical MSE advection computed as the difference between $\overline{F^{\text {net }}}$ and the horizontal moist enthalpy advection, which therefore includes the residual necessary to close the budget (note the opposite sign in Fig. 4, right, and Fig. 5, left). Given that the MSE stratification is mostly negative in pressure coordinates, the vertical motion is qualitatively coupled with the vertical advection of MSE: ascending and descending motions are expected to occur where the sum of the net energy input and advective fluxes is positive and negative, respectively. This qualitative correspondence does not, however, imply a quantitative mapping, since the MSE stratification varies spatially. In the baiu region and the northwestern Pacific Ocean, the fact that precipitation occurs in a region of otherwise negative net energy input into the atmospheric column invalidates the traditional tropical-subtropical balance in which ascending motion is correlated with positive net energy input into the atmospheric column. The horizontal moist enthalpy advection therefore plays an essential role in sustaining the MB rainfall band.

In the seasonal evolution of the EASM, both the net energy into the atmosphere and the horizontal moist enthalpy advection vary in location and intensity. In the pre-MB season, $\overline{F^{\text {net }}}$ is positive over continents and tropical oceans but decreases rapidly poleward over the oceanic regions (Fig. 4a). The horizontal moist enthalpy advection $-\langle\overline{\mathbf{v} \cdot \nabla E}\rangle$ is prevailingly negative and offsets $\overline{F^{\text {net }}}$ in most continental and tropical regions, except over and to the east of the TP (Fig. 4b). The sum of these two terms is the vertical MSE advection (Fig. 4c or 5a), whose pattern resembles the precipitation pattern in the pre-MB season (Fig. 5d). In turn, the precipitation pattern is spatially correlated with the pattern of horizontal moist enthalpy advection everywhere, except over southeast China, where vertical ascending motion is colocated with positive $\overline{F^{\text {net }}}$. To the north of the rainfall band, strong negative horizontal moist enthalpy advection is balanced by vertical descending motion. Over the oceans, precipitation occurs in regions of weak energy flux but strong positive horizontal moist enthalpy advection; however, the horizontal moist enthalpy advection cannot balance the strong negative energy flux in the midlatitudes, resulting in an unfavorable region for convection.

During the MB season, the energy flux (Fig. 4d) decreases in the MB region and the northwest Pacific Ocean, mainly because of increased reflection of insolation due to increased cloud cover and decreased latent heat flux over oceanic regions. In the tropical and subtropical oceans, however, as the SSTs continue to increase, evaporation from the ocean increases accordingly, resulting in an increase in net energy input into the atmospheric column. Nevertheless, convection is not favored to the south of the MB region despite higher SST values (Sampe and Xie 2010; Fig. 5e). Sampe and Xie (2010) attribute this preference of convection over the northwest Pacific Ocean with lower SSTs to the combined effect of the midtropospheric warm air advection and weather disturbances steered by the subtropical westerly jet. In the framework of the MSE budget, this preference is largely governed by the horizontal moist enthalpy advection: to the south of the MB region, regardless of higher SSTs, the net energy is weak and cannot trigger convection; the horizontal 

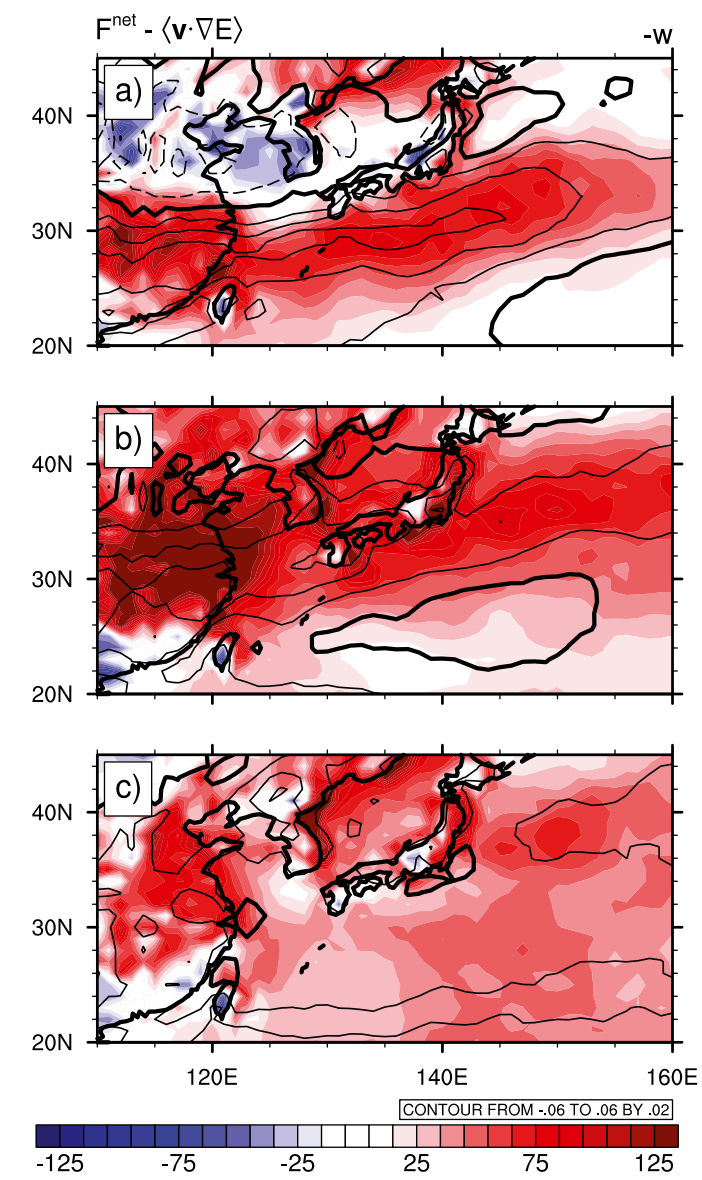
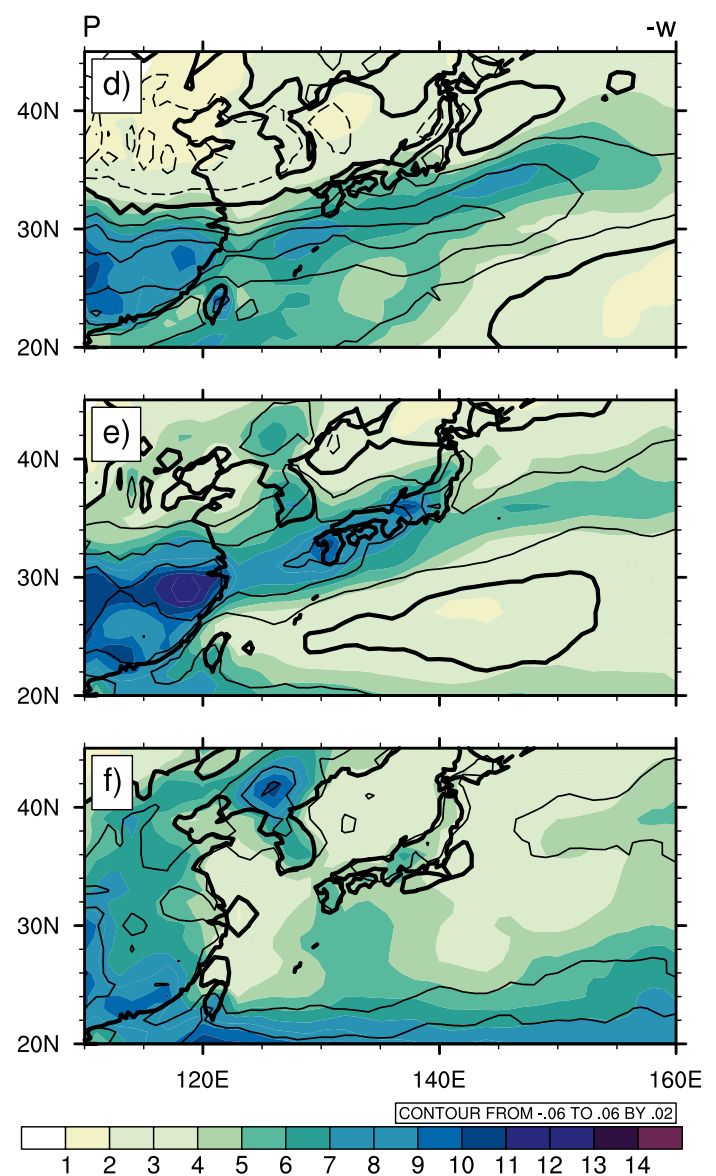

FIG. 5. (left) Vertical MSE advection computed as $\overline{F^{\text {net }}}-\langle\overline{\mathbf{v} \cdot \nabla E}\rangle$ (color shading, $\mathrm{W} \mathrm{m}^{-2}$ ) and (right) GPCP climatological mean precipitation (color shading, $\mathrm{mm} \mathrm{day}^{-1}$ ). Rows are as in Fig. 4. In all panels, contours show vertical velocity ( $\mathrm{Pa} \mathrm{s}^{-1}$, interval $0.02 \mathrm{~Pa} \mathrm{~s}^{-1}$ ), with upward (downward) motion in solid (dashed) contours; the zero contour is thickened.

moist enthalpy advection is large over the northwestern Pacific while hardly affecting or even suppressing convection in the subtropical ocean. The MB rainfall band, similar to what is seen in the pre-MB season, is primarily sustained by the horizontal moist enthalpy advection, with its overall structure and location resulting from both the net energy input and the horizontal moist enthalpy advection (Fig. $4 \mathrm{f}$ or $5 \mathrm{~b}$ ). In addition, over the meiyu region, the horizontal moist enthalpy advection is positive before and during the MB season, but becomes negligible in the post-MB season.

In the post-MB season, the net energy flux over the ocean increases in tropical and subtropical latitudes but decreases in the midlatitudes. Over the continents, it decreases in most regions (Fig. 4g). The horizontal moist enthalpy advection displaces poleward and becomes less intense, resulting in a sharp reduction in horizontal moist enthalpy advection over the $\mathrm{MB}$ region but a slight increase to both its south and north (Fig. 4h). As a result, the MB region is less favored energetically and a bifurcation of the vertical MSE advection is formed to the south and north of the MB region (Fig. $4 \mathrm{i}$ or $5 \mathrm{c}$ ). This pattern of vertical MSE advection explains the suppression of rainfall and revival of convection over the subtropical northwestern Pacific during and after the MB season: during the MB season, despite high SSTs, strong negative horizontal moist enthalpy advection is balanced by descending motions in this region; after the MB season, the increase in net energy flux into the atmosphere combined with a reduction in negative horizontal moist enthalpy advection provides a favorable environment for the development of convection (Fig. 5f).

The similarity between the vertical MSE advection and the precipitation pattern in the three subsequent seasons using two independent datasets (Fig. 5, cf. left and right) gives us confidence in the validity of using the MSE framework to study the climatology and seasonality of the EASM. 


\section{c. Energy advection decomposition}

During the MB season, both $\overline{F^{\text {net }}}$ and horizontal moist enthalpy advection are important in sustaining the rainfall in the meiyu region; however, in the baiu region and the northwestern Pacific, energy input into the atmosphere is negative, and the horizontal moist enthalpy advection alone sustains the rainfall. Given that the horizontal moist enthalpy advection plays an essential role in positioning the stationary $\mathrm{MB}$ rainfall band, heuristically we expect the stationary eddy fluxes to be the dominant terms in the horizontal moist enthalpy advection. Here we decompose the horizontal moist enthalpy advection into mean, transient, and stationary eddy fluxes. As explained in section $2,(\cdot)^{\prime}$ and $(\cdot)^{*}$ denote deviations from the time $\overline{(\cdot)}$ and zonal $[\cdot]$ mean, respectively. Hence, the time mean advection of the atmospheric energy $\langle\overline{\mathbf{v} \cdot \nabla E}\rangle$ can be written as

$$
\begin{aligned}
\langle\overline{\mathbf{v} \cdot \boldsymbol{\nabla} E}\rangle= & \langle[\overline{\mathbf{v}}] \cdot[\overline{\mathbf{\nabla} E}]\rangle+\left\langle[\overline{\mathbf{v}}] \cdot \bar{\nabla} E^{*}\right\rangle+\left\langle\overline{\mathbf{v}^{*}} \cdot[\bar{\nabla} E]\right\rangle \\
& +\left\langle\overline{\mathbf{v}^{*}} \cdot \bar{\nabla} E^{*}\right\rangle+\left\langle\overline{\mathbf{v}^{\prime} \cdot \nabla E^{\prime}}\right\rangle .
\end{aligned}
$$

The first term on the right-hand side is the zonal-mean energy advection by the zonal-mean flow; the second term is the advection of the stationary eddy energy by the zonal-mean flow; the third term is the advection of the zonal-mean energy by the stationary eddy velocity; the fourth term is the advection of the stationary eddy energy by the stationary eddy velocity; and the fifth term is the advection of the transient eddy energy by the transient eddies.

The zonal-mean term $\langle[\overline{\mathbf{v}}] \cdot[\bar{\nabla} E]\rangle$ is very small compared to the other terms and can be neglected (not shown). All other terms are shown in Fig. 6 (left), together with separate contributions by the dry enthalpy (Fig. 6, center) and latent energy (Fig. 6, right). Comparing the horizontal dry enthalpy advection and latent energy advection on the MB region during the MB season, we find that the dry enthalpy component tends to dominate in the core of the $\mathrm{MB}$ region, with the latent energy advection becoming important only over the midlatitude ocean. Previous evaluations based on observational and numerical studies argued latent energy advection through the lower-level southwesterly transport of moisture from the tropical oceans, including the Bay of Bengal (BOB), the SCS, and the western Pacific, to be the major source of energy for the development and maintenance of the rainfall band over the MB region (e.g., Ninomiya and Murakami 1987; Kuo et al. 1986; Wang 1987; Wang et al. 1993). However, our analysis deemphasizes the importance of moisture advection as an energy supply and confirms that the MB rainfall band, from a large-scale perspective, is mainly the result of dry enthalpy advection (Sampe and Xie 2010). As we have identified the horizontal dry enthalpy advection as the main component in the horizontal moist enthalpy advection, we now focus on its eddy fluxes and assess their relative contributions to the moist enthalpy advection.

The total dry enthalpy advection results from the advection of the stationary eddy dry enthalpy by the zonal-mean flow $-\left\langle\left[c_{p} \overline{\mathbf{v}}\right] \cdot \bar{\nabla} T^{*}\right\rangle$ (Fig. 6e), the advection of the zonal-mean dry enthalpy by the stationary eddy velocity $-\left\langle c_{p} \overline{\mathbf{v}^{*}} \cdot \overline{[\nabla T]}\right\rangle$ (Fig. $6 \mathrm{~h}$ ), the pure stationary eddy flux $-\left\langle c_{p} \overline{\mathbf{v}^{*}} \cdot \bar{\nabla} T^{*}\right\rangle$ (Fig. 6k), and the transient eddy flux $-\left\langle c_{p} \overline{\mathbf{v}^{\prime} \cdot \nabla T^{\prime}}\right\rangle$ (Fig. 6n). All the three stationary eddy fluxes have positive dry enthalpy advection into the MB region and the northwestern Pacific; however, the transient eddy flux, which is expected to diverge atmospheric energy away from the subtropics into higher latitudes, has opposite sign in the MB region. The first two terms, $-\left\langle\left[c_{p} \overline{\mathbf{v}}\right] \cdot \overline{\nabla T^{*}}\right\rangle$ and $-\left\langle c_{p} \overline{\mathbf{v}^{*}} \cdot \overline{[\nabla T]}\right\rangle$, vanish when one takes the global zonal mean, but represent stationary eddy-mean flow interactions, which locally are of primary importance. The pure stationary eddy flux and the transient eddy flux are comparable in magnitude to the other two stationary eddy fluxes, but they appear to have similar spatial patterns of opposite sign, such that their combined contribution to the total dry enthalpy advection over the overall MB region and the northwestern Pacific is negligible. This is even more evident if we look at the zonal and meridional components of dry enthalpy advection (not shown), which are dominated by $-\left\langle\left[c_{p} \overline{\mathbf{v}}\right] \cdot \bar{\nabla} T^{*}\right\rangle$ and $-\left\langle c_{p} \overline{\mathbf{v}^{*}} \cdot \overline{[\nabla T]}\right\rangle$, respectively, with a negligible contribution from the corresponding components of the pure stationary and transient fluxes. While we still do not understand to what extent this cancellation might be a coincidence or an intrinsic feature of the EASM, we also observe it in the numerical simulations discussed in the next section. For this reason, in the following we primarily focus on the two stationary eddy fluxes that depend on stationary eddy-mean flow interactions, that is, the advection of the stationary eddy dry enthalpy by the zonal-mean flow, $-\left\langle\left[c_{p} \overline{\mathbf{v}}\right] \cdot \overline{\nabla T^{*}}\right\rangle$, and the advection of the zonalmean dry enthalpy by the stationary eddy velocity, $-\left\langle c_{p} \overline{\mathbf{v}^{*}} \cdot \overline{[\nabla T]}\right\rangle$.

The $[\overline{\mathbf{v}}] \cdot \bar{\nabla} T^{*}$ term is approximately equal to the product of the zonal mean zonal wind $[\bar{u}]$ and the longitudinal stationary thermal gradient due to zonal asymmetries $\partial_{x} \overline{T^{*}}$. The $\overline{\mathbf{v}^{*}} \cdot[\bar{\nabla} T]$ term is equal to the product of the meridional stationary eddy velocity $\overline{v^{*}}$ and zonal mean meridional temperature gradient $\left[\partial_{y} \bar{T}\right]$. The zonal mean zonal wind and the zonal mean meridional temperature gradient are primarily determined by the global energy and momentum budgets and barely affected by local forcings, especially in Northern Hemisphere 

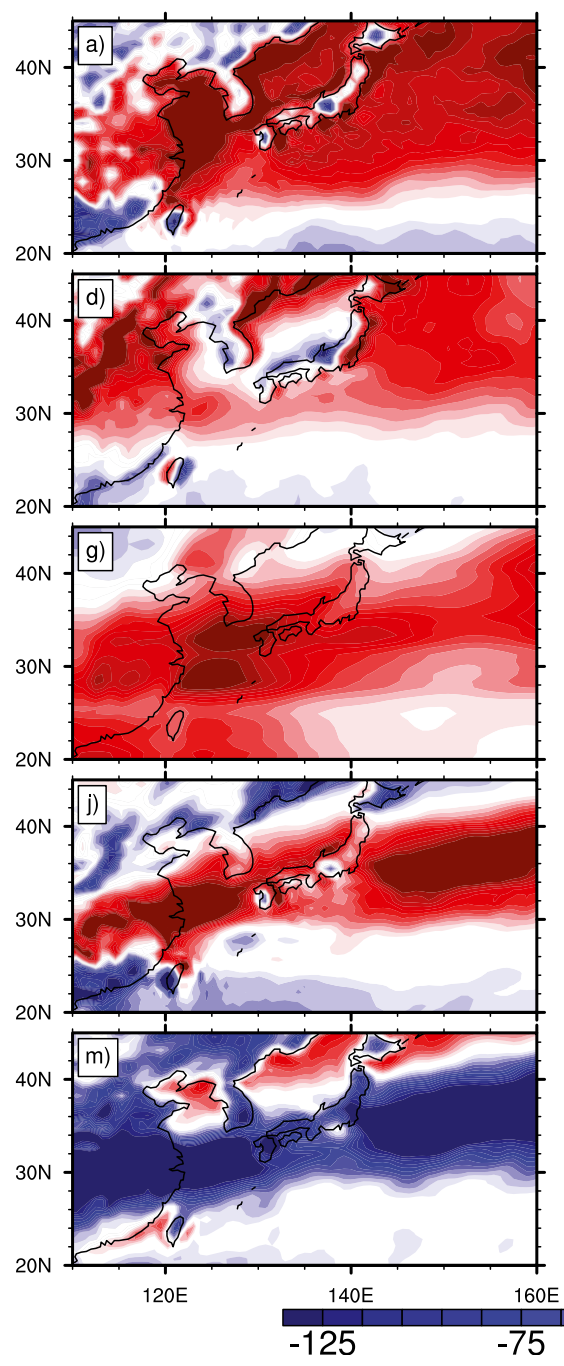
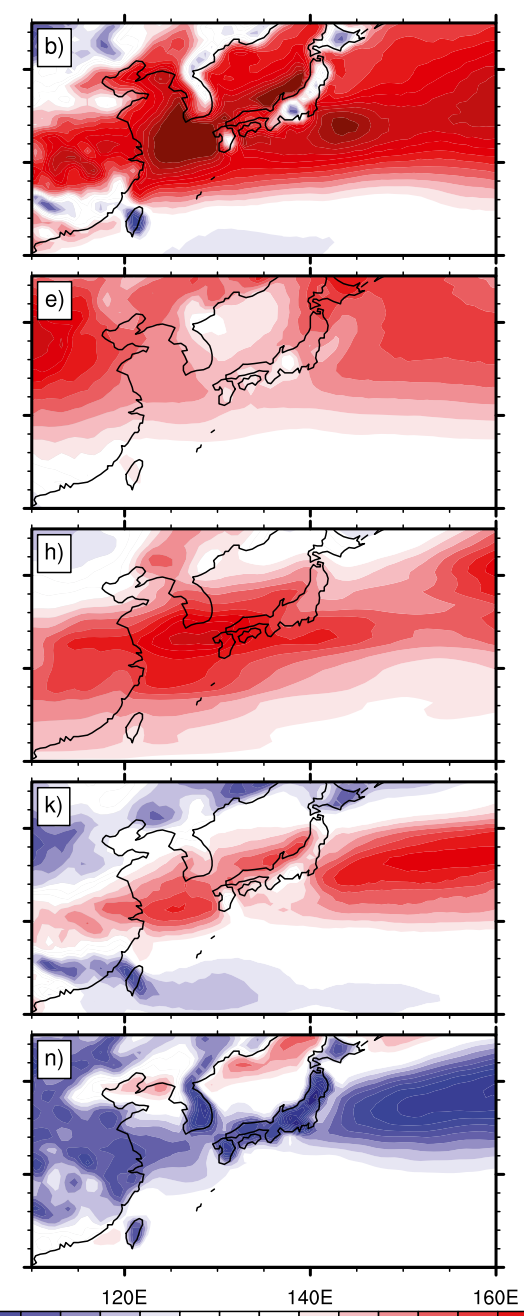

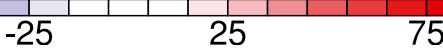
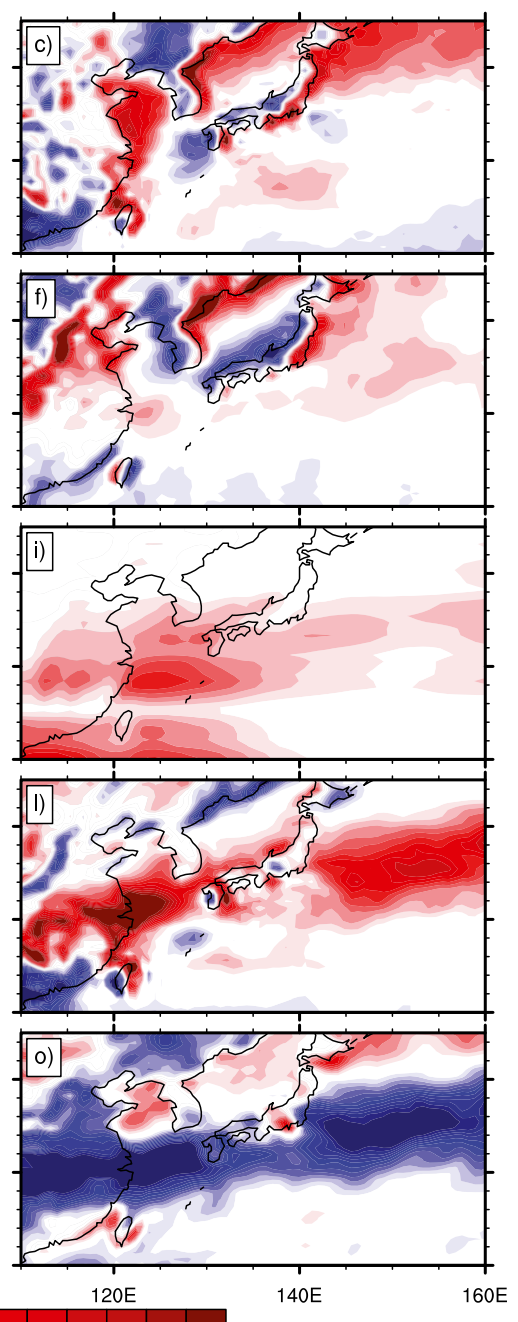

125

FIG. 6. Eddy decomposition of the vertical integral of the (left) horizontal moist enthalpy advection $-\langle\overline{\mathbf{v} \cdot \nabla E}\rangle$, (center) horizontal dry enthalpy advection $-\left\langle\overline{c_{p} \mathbf{v} \cdot \nabla T}\right\rangle$, and (right) latent energy advection $-\left\langle\overline{L_{v} \mathbf{v} \cdot \nabla q}\right\rangle$ during the MB season. Rows indicate the (top) total advection $-\langle\overline{\mathbf{v} \cdot \nabla(\cdot)}\rangle$, (second row) advection of the stationary eddy energy by the zonal-mean flow $-\left\langle[\overline{\mathbf{v}}] \cdot \overline{\left.\nabla(\cdot)^{*}\right\rangle}\right.$, (third row) advection of the zonal-mean energy by the stationary eddy velocity $-\left\langle\overline{\mathbf{v}^{*}} \cdot[\overline{\nabla(\cdot)}]\right\rangle$, (fourth row) advection of the stationary eddy energy by the stationary eddy velocity, or pure stationary eddy $-\left\langle\overline{\mathbf{v}^{*}} \cdot \overline{\left.\nabla(\cdot)^{*}\right\rangle}\right.$, and (bottom) advection of the transient eddy energy by the transient eddy velocity $\left.-\overline{\left\langle\mathbf{v}^{\prime} \cdot \nabla(\cdot)^{\prime}\right\rangle}\right\rangle$. (Color shading is in $\mathrm{W} \mathrm{m}^{-2}$.)

summer (cf. Peixoto and Oort 1992). Hence, the presence of the TP will not influence zonal mean quantities but will be primarily manifest in the local longitudinal thermal gradient due to zonal asymmetries $\partial_{x} \overline{T^{*}}$ and

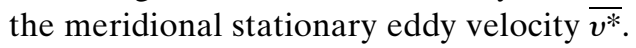

The zonal gradient of the stationary temperature term $\partial_{x} T^{*}$ is due to the land-sea thermal contrast and the TP thermal effects. Given that during the MB season the predominant winds are still eastward, both locally over the TP and the MB region and in the zonal average at these latitudes, the land-sea differential heating results in warm air advection in the downstream of the TP. Such inhomogeneous heating is reinforced by the presence of the TP, which is heated up rapidly during the spring and summer. The factor $[\bar{u}] \partial_{x} \overline{T^{*}}$ is the backbone of the theory in Sampe and Xie (2010), in which the advection of warm air from the TP to the MB region is argued to be the major forcing of the MB rainfall system. The presence of the TP can also contribute to the meridional stationary eddy velocity $\overline{v^{*}}$ in its downstream by both thermal and mechanical effects. The thermal effect can drive lower-level cyclonic circulation around the TP, which enhances the southerlies in the MB region. The mechanical interaction between the subtropical westerly jet and the TP induces a region of lower-level convergence in its downstream, with southerlies 

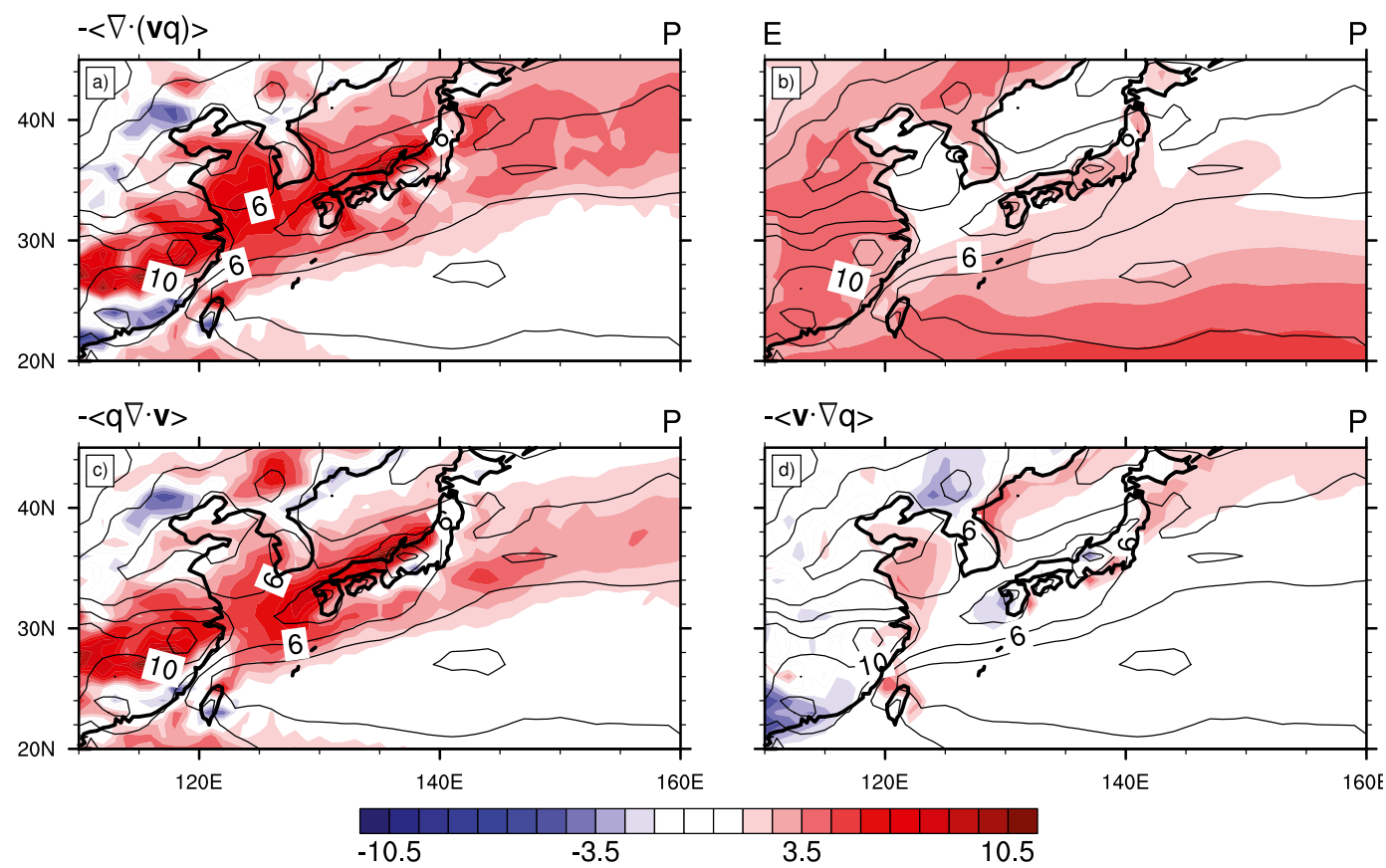

FIG. 7. Moisture budget for the MB season. (a) Vertically integrated moisture flux convergence $-\langle\overline{\nabla \cdot(\mathbf{v} q)}\rangle$, (b) evaporation, (c) product of moisture and wind convergence $-\langle\overline{q \nabla \cdot \mathbf{v}}\rangle$, and (d) moisture advection $-\langle\overline{\mathbf{v} \cdot \nabla q}\rangle$. (Color shading is in mm day ${ }^{-1}$.) Contours are precipitation with an interval $1 \mathrm{~mm} \mathrm{day}^{-1}$.

to the south and northerlies to the north of the MB region.

In the zonal mean, transient and stationary eddy fluxes are the primary means by which energy is transported poleward in the extratropics to satisfy the global energy budget. Zonal asymmetries can create regions of enhanced and suppressed eddy transport through local effects. For instance, in a recent work, Kaspi and Schneider (2013) show that a zonally asymmetric surface heating in an otherwise uniform slab ocean can shape storm tracks by modulating local baroclinicity through stationary fluxes. In the MB region, the local moist enthalpy advection arises, as shown by our analysis above, because of zonal asymmetries due to both land-sea contrast and the TP. The precise role of the TP in the local moist enthalpy advection, which cannot be assessed by means of observations only, will be more systematically explored using numerical simulations in the next section.

\section{d. Moisture budget}

The distribution of the net precipitation in the MB rainfall needs to satisfy the moisture budget:

$$
\left\langle\overline{\partial_{t} q}\right\rangle+\langle\overline{\nabla \cdot(\mathbf{v} q)}\rangle+\left\langle\overline{\partial_{p}(\omega q)}\right\rangle=-\bar{P}+\bar{E}
$$

Averaged over a climatological period, the tendency term $\left\langle\overline{\partial_{t} q}\right\rangle$ and the vertical term $\left\langle\overline{\partial_{p}(\omega q)}\right\rangle$ can be neglected (not shown). The convergence of moisture flux $-\langle\overline{\nabla \cdot(\mathbf{v} q)}\rangle$ can be decomposed into the moisture advection $-\langle\overline{\mathbf{v} \cdot \nabla q}\rangle$ and the product of moisture and wind convergence $-\langle\overline{q \nabla \cdot \mathbf{v}}\rangle$. In most of the MB region, particularly over the oceanic regions, surface evaporation is limited (Fig. 7b) and the moisture flux convergence (Fig. 7a) plays a more dominant role in water vapor supply. Further decomposition indicates that the moisture flux convergence primarily arises from the wind convergence (Fig. $7 \mathrm{c}$ ) over the MB region, whereas moisture advection becomes dominant in midlatitude oceanic regions (Fig. 7d), consistent with the results discussed in the previous section.

As we did for the MSE budget, we decompose $\overline{q \nabla \cdot \mathbf{v}}$ into mean $(-[\bar{q}][\overline{\nabla \cdot \mathbf{v}}])$, stationary $\left(-\overline{q^{*}}[\overline{\boldsymbol{\nabla} \cdot \mathbf{v}}]\right.$, $-[\bar{q}] \overline{\boldsymbol{\nabla} \cdot \mathbf{v}^{*}},-\overline{\left.q^{*} \boldsymbol{\nabla} \cdot \mathbf{v}^{*}\right)}$, and transient eddy fluxes $\left(-\overline{q^{\prime} \mathbf{\nabla} \cdot \mathbf{v}^{\prime}}\right)$. The dominant term is $-[\bar{q}] \overline{\nabla \cdot \mathbf{v}^{*}}$ (Fig. 8a), while the zonal asymmetries due to water vapor are negligible (Fig. 8b). As argued above, the presence of the TP will primarily impact stationary quantities, including the stationary eddy convergence term $-\overline{\nabla \cdot \mathbf{v}^{*}}$. The pure stationary eddy flux $-\overline{q^{*} \boldsymbol{\nabla} \cdot \mathbf{v}^{*}}$ is comparable to the $-[\bar{q}] \overline{\boldsymbol{\nabla} \cdot \mathbf{v}^{*}}$ term over the meiyu region, but becomes negligible over the baiu and oceanic regions (Fig. 8c). The transient eddy flux $-\overline{q^{\prime} \mathbf{\nabla} \cdot \mathbf{v}^{\prime}}$ plays only a minor role.

The results discussed so far identify the longitudinal thermal gradient due to zonal asymmetries $\partial_{x} T^{*}$ and the meridional stationary eddy velocity $\overline{v^{*}}$ as important 


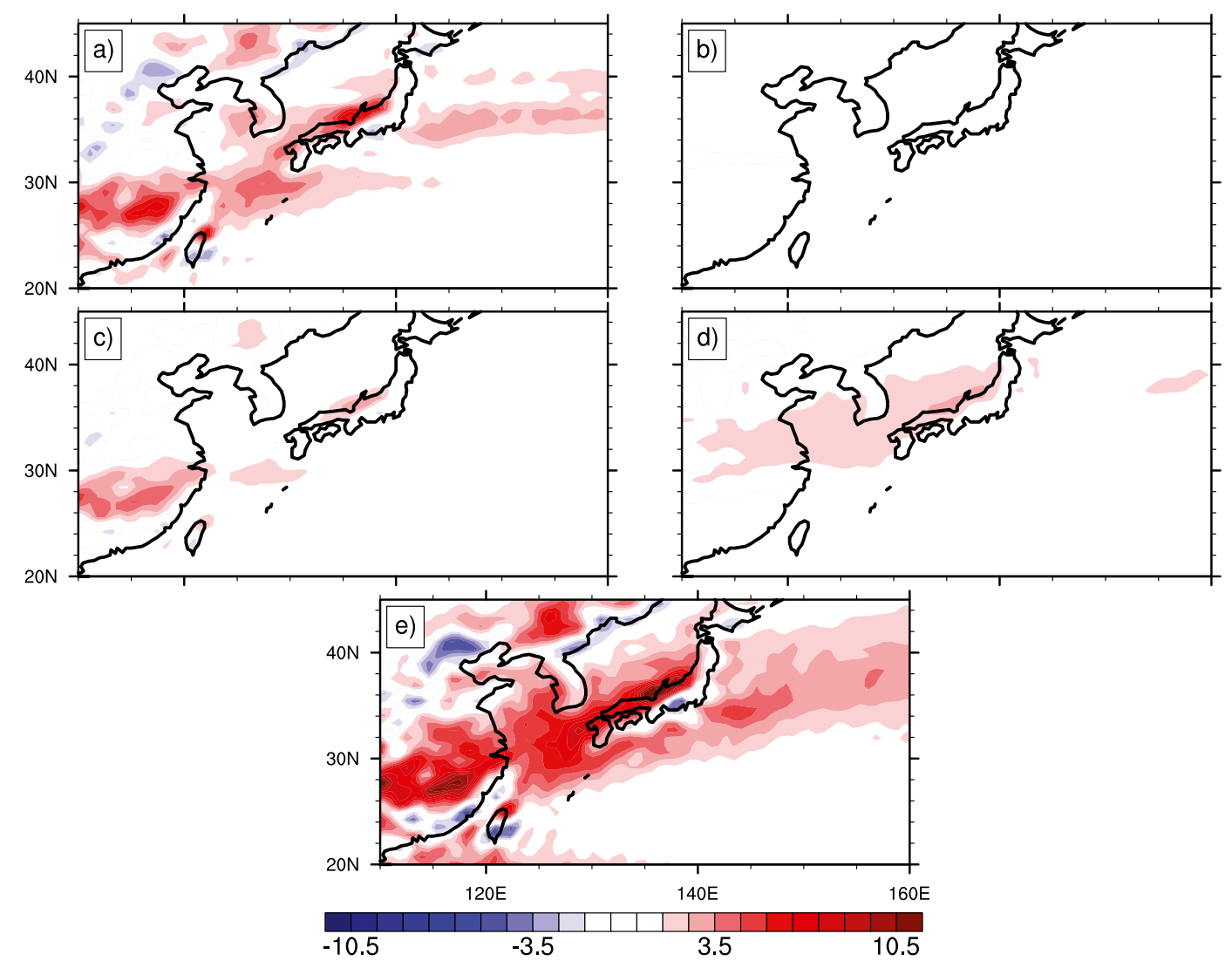

FIG. 8. Eddy decomposition of the vertical integral of (e) the product of moisture and wind convergence $-\langle\overline{q \nabla \cdot \mathbf{v}}\rangle$ into the products of (a) the stationary eddy convergence and the zonal-mean specific humidity $-\left\langle[\bar{q}] \bar{\nabla} \cdot \mathbf{v}^{*}\right\rangle$, (b) the zonalmean flow convergence and the stationary specific humidity $-\left\langle\overline{q^{*}}[\overline{\boldsymbol{\nabla} \cdot \mathbf{v}}]\right\rangle$, (c) the stationary eddy convergence and the stationary specific humidity or pure stationary eddy $-\left\langle\overline{q^{*} \boldsymbol{\nabla} \cdot \mathbf{v}^{*}}\right\rangle$, and (d) the transient flow convergence and the transient specific humidity $-\left\langle\overline{q^{\prime} \mathbf{\nabla} \cdot \mathbf{v}^{\prime}}\right\rangle$ during the MB season. (Color shading is in $\mathrm{W} \mathrm{m}^{-2}$.)

dynamical factors implicated in the MB formation. In the next section, we perform numerical simulations with the AM2.1 AGCM to explore how the presence or absence of the TP affects the MB rainfall through these exposed factors.

\section{Numerical experiments}

Here we analyze the AM2.1 control simulation and the experiment simulation to explore the role of the TP on the existence of the EASM. The control experiment simulates reasonably well the seasonal evolution of the EASM (Fig. 9). However, the model underestimates the precipitation over the MB region, possibly because of coarse resolution and deficiencies in the convective parameterization. ${ }^{3}$

\footnotetext{
${ }^{3}$ In the AM2.1 control simulation, the MB season is anticipated by around 30 days. Here we define the MB season in the control simulation as the 30 days in which the precipitation over the MB region reaches its maximum.
}

When the TP is removed, the MB rainfall almost disappears and oceanic precipitation in the deep tropics slightly increases. This confirms that the TP plays a fundamental role in the existence of the EASM, in agreement with previous studies (e.g., Kitoh 2004; Park et al. 2012; Wu et al. 2012).

Figure 10 shows the precipitation distribution and the vertical MSE advection calculated as the difference between $\overline{F^{\text {net }}}$ and horizontal moist enthalpy advection in the control run and experiment run. The precipitation is strongly coupled with midtropospheric vertical velocity, which is highly correlated with the vertical MSE advection. In the presence of the TP, a tilted, intensified rainfall band expands across the MB region and to the northwestern Pacific. In the absence of the TP, however, the precipitation over the MB region is significantly weakened and sparsely distributed. The suppression of precipitation over higher SST regions is not observed in the absence of the TP. The similarity between the precipitation pattern and the vertical MSE advection further confirms the feasibility of our framework in capturing the precipitation in the MB season. 

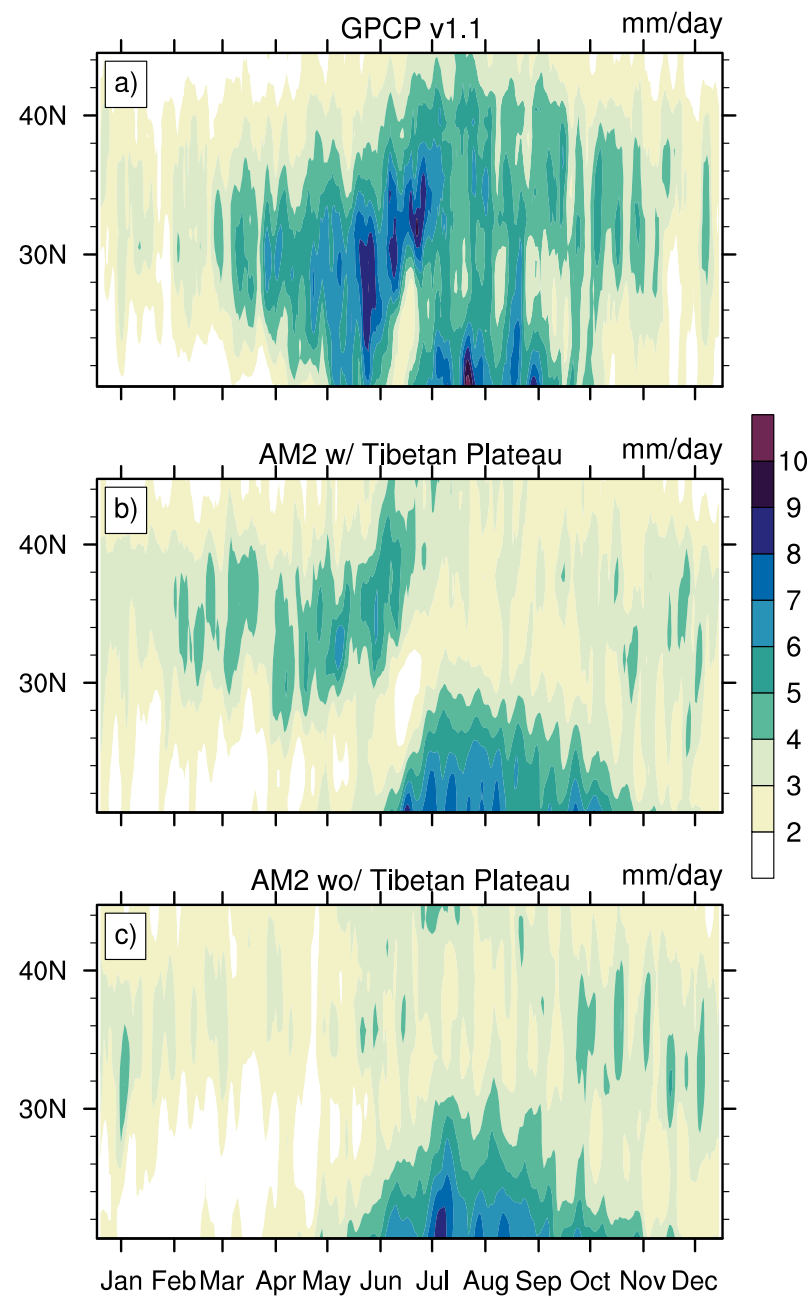

FIG. 9. Hovmöller plot of precipitation averaged from $110^{\circ}$ to $160^{\circ} \mathrm{E}$ in (a) GPCP and AM2.1 simulations (b) with and (c) without the TP.

The difference between the experiment run and control run in the vertical MSE advection mainly results from changes in horizontal moist enthalpy advection rather than changes in net energy flux over the MB region (not shown). The change in horizontal moist enthalpy advection is dominated by changes in the horizontal dry enthalpy advection, with smaller or opposite signed changes in latent energy advection (Figs. 11a,b). The presence of the TP creates a narrow and tilted band of positive dry enthalpy advection in its downstream, highly resembling the rainfall pattern. Strong negative advection, which is balanced by descending motion, appears to the north and south of the positive advection zone.

Performing the same decomposition of the dry enthalpy advection in mean and eddy terms as the one presented in section $4 \mathrm{c}$, we find that the main contribution to the total dry enthalpy advection (Fig. 11a) arises from the advection of the zonal mean dry enthalpy by stationary eddies $-\left\langle c_{p} \overline{\mathbf{v}^{*}} \cdot[\overline{\nabla T}]\right\rangle$ (Fig. 11d). Interestingly the advection of the stationary eddy dry enthalpy by the zonal-mean flow $-\left\langle c_{p}[\overline{\mathbf{v}}] \cdot \bar{\nabla} T^{*}\right\rangle$ (Fig. 11c) only exerts a minor and relatively local influence over the near downstream of the TP. Similar changes occur in the midtropospheric warm air advection at $500 \mathrm{hPa}$ (not shown). This result shows that local heating over the TP, which reinforces the land-sea thermal contrast, and hence the longitudinal temperature gradient, only impacts the near downstream of the TP, leaving the baiu region and the northwestern Pacific largely unaffected. However, the presence of the TP, through both its mechanical effect and changes in the circulation due to the thermal effect, influences the meridional stationary eddy velocity and helps sustain the MB rainfall band. The pure stationary eddy flux and the transient eddy flux both increase in magnitude in the presence of the TP (Figs. 11e,f), but their combined contribution to the total dry enthalpy advection remains negligible.

To further expose the role of the TP in determining patterns of dry enthalpy advection necessary to maintain the MB front, we compute the anomalous advection of the mean dry enthalpy by stationary eddies as the difference between the control $\left(\overline{\mathbf{v}_{c}^{*}} \cdot[\overline{\nabla T}]_{c}\right)$ and experiment $\left(\overline{\mathbf{v}_{e}^{*}} \cdot[\bar{\nabla} T]_{e}\right)$ simulations and we further partition it in such way that

$$
\begin{aligned}
\left\langle\delta\left(\overline{\mathbf{v}^{*}} \cdot[\overline{\mathbf{\nabla} T}]\right)\right\rangle= & \left\langle\delta \overline{\mathbf{v}^{*}} \cdot[\overline{\mathbf{\nabla} T}]_{e}\right\rangle+\left\langle\overline{\mathbf{v}_{e}^{*}} \cdot \delta[\overline{\mathbf{\nabla} T}]\right\rangle \\
& +\left\langle\delta \overline{\mathbf{v}^{*}} \cdot \delta[\overline{\nabla T}]\right\rangle,
\end{aligned}
$$

where $\delta(\cdot)$ is defined as the difference between the experiment with the TP and without the TP [i.e., $\delta(\cdot)=$ $(\cdot)_{c}-(\cdot)_{e}$, where the subscript $c$ and $e$ denote the experiment with the TP and without the TP, respectively]. The result (not shown) indicates that the total difference $\left\langle\delta\left(\overline{\mathbf{v}^{*}} \cdot[\bar{\nabla} T]\right)\right\rangle$ is almost entirely due to changes in $\mathbf{v}^{*}$, $\left\langle\delta \overline{\mathbf{v}^{*}} \cdot[\bar{\nabla} T]_{e}\right\rangle$, while the difference in the zonal mean temperature gradient, $[\bar{\nabla} T]$ in $\left\langle\overline{\mathbf{v}^{*}} \cdot[\bar{\nabla} T]\right\rangle$, and covariation $\left\langle\delta \overline{\mathbf{v}^{*}} \cdot \delta[\overline{\mathbf{\nabla} T}]\right\rangle$ are negligible.

The same analysis is performed on the moisture budget and it is found that the presence of the TP primarily influences the stationary eddy convergence term in the product of the zonal mean moisture and stationary eddy convergence $-\left\langle[\bar{q}] \overline{\nabla \cdot \mathbf{v}^{*}}\right\rangle$ (Fig. 12). The presence of the TP barely exerts any influence on the zonal mean atmospheric specific humidity. The enhanced moisture flux convergence therefore is primarily due to enhanced wind convergence, or more specifically lower-level convergence, because the term $-\left\langle[\bar{q}] \bar{\nabla} \cdot \mathbf{v}^{*}\right\rangle$ is highly weighed by the water vapor content, mostly confined in the lower troposphere. 

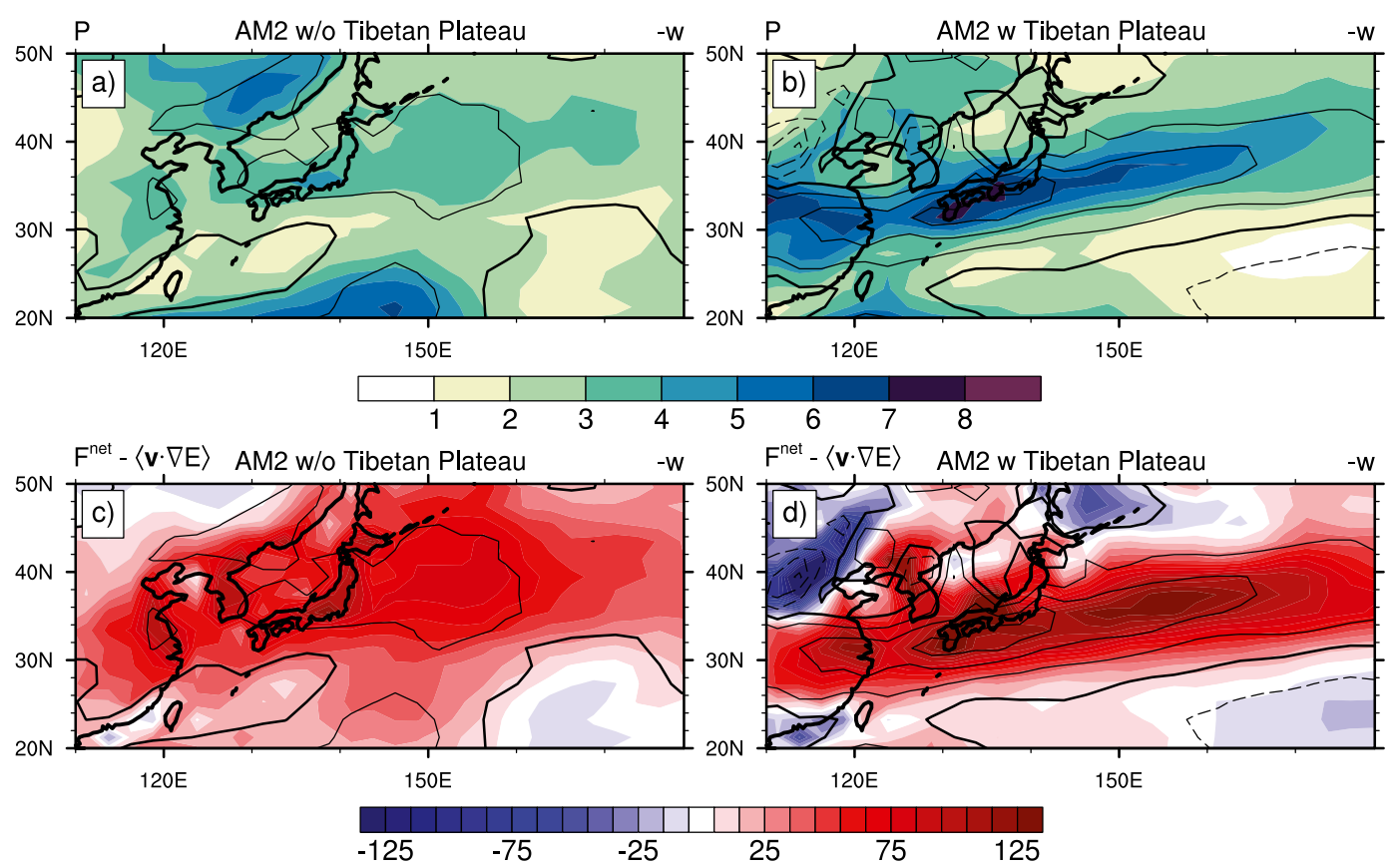

FIG. 10. (top) Precipitation (color shading, $\mathrm{mm} \mathrm{day}^{-1}$ ) and (bottom) vertical MSE advection (color shading, $\mathrm{W} \mathrm{m}^{-2}$ ) of AM2.1 integration (right) with and (left) without the TP during the MB season. Contours indicate vertical ascending velocity $\left(\mathrm{Pa} \mathrm{s}^{-1}\right.$, interval $\left.0.02 \mathrm{~Pa} \mathrm{~s}^{-1}\right)$ at $500 \mathrm{hPa}$.

The zonal mean temperature gradient, $[\bar{\nabla} \bar{T}]$, or equivalently the zonal-mean latitudinal temperature gradient $\left[\overline{\partial_{y} T}\right]$, is nearly invariant in the troposphere in the MB region (not shown), allowing us to extract the temperature gradient term from the vertical integral of the advection of the zonal mean dry enthalpy by stationary eddies, that is, $-\left\langle c_{p} \overline{\mathbf{v}^{*}} \cdot[\bar{\nabla} T]\right\rangle \approx-c_{p}\left\langle\overline{v^{*}}\right\rangle\left[\overline{\partial_{y} T}\right]$. This reveals that the pattern of change in the advection of the zonal mean dry enthalpy by stationary eddies is similar to that in meridional stationary eddy velocity, or meridional velocity, given that the change in the zonal mean meridional velocity is negligible in the simulations (Fig. 11d).

The meridional stationary eddy velocity $\overline{v^{*}}$ shows a strong first baroclinic structure in the MB region (averaged from $110^{\circ}$ to $160^{\circ} \mathrm{E}$ ) in both the reanalysis data (Fig. 13a) and the AM2.1 numerical simulation in the presence of the TP (Fig. 13b), with strong southerlies in the middle and lower troposphere and northerlies in the upper troposphere and stratosphere. It also shows pronounced meridional convergence almost throughout the entire troposphere, with maximum up to $200 \mathrm{hPa}$, between $30^{\circ}$ and $40^{\circ} \mathrm{N}$. In the absence of the TP, the strength of the meridional stationary eddy velocity is significantly weakened, and is accompanied by a sharp reduction in its convergence in the free troposphere (Fig. 13c). The difference between the control and experiment runs is shown in Fig. 13d, with the presence of the TP causing pronounced southerly wind to the south and northerly wind to the north of the MB region, and hence strong convergence over the MB region. The spatial patterns of changes in the vertically integrated meridional stationary eddy velocity convergence and stationary wind fields are shown in Figs. 11a,d. The reinforced southerlies over the MB region in the presence of the TP bring abundant warm and moist air from tropical oceans to the MB region and the northwestern Pacific. The enhanced northerlies to the north of the MB region prevent the southerlies from invading farther north and are associated with the meridional wind convergence (Figs. 13b and 14a). The meridional convergence has to be balanced by zonal divergence if integrated vertically. In pressure coordinates and neglecting topographic effects on boundary velocity, the continuity equation

$$
\langle\nabla \cdot \overline{\mathbf{v}}\rangle=0
$$

can be written as $\left\langle\overline{\partial_{x} u}+\overline{\partial_{y} v}\right\rangle=\left\langle\overline{\partial_{x} u^{*}}+\overline{\partial_{y} v^{*}}\right\rangle=0$. Therefore, the convergence of the meridional stationary velocity (Fig. 13a) is coupled with divergence of the zonal stationary velocity (not shown). The zonal wind diverges over the MB region due to the interaction with the TP and the effect from the subtropical high, as well as possible influences by the precipitation system itself. The lower-level wind convergence (integrated from surface to $700 \mathrm{hPa}$; Fig. 14c), due to the meridional wind 

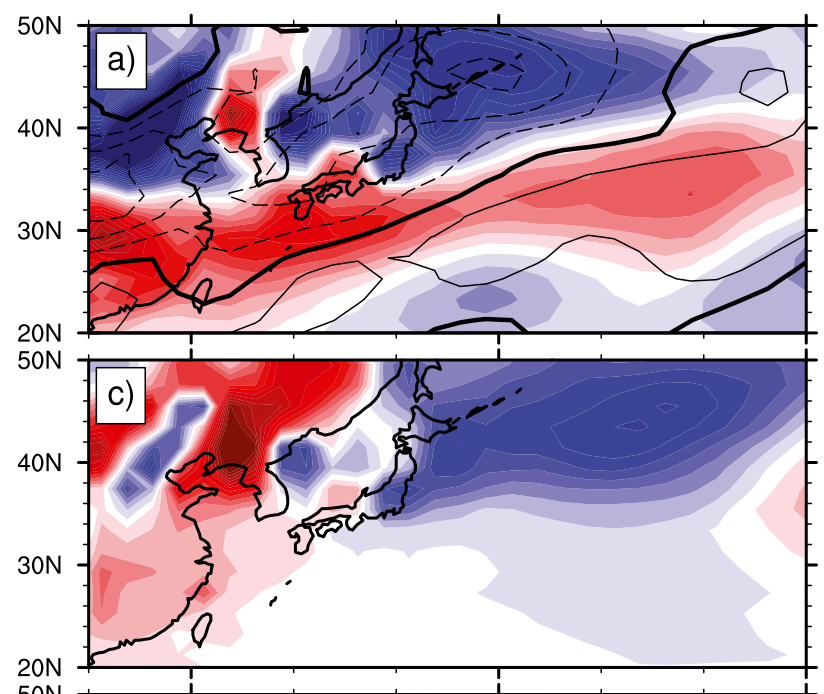

$50 \mathrm{~N}$

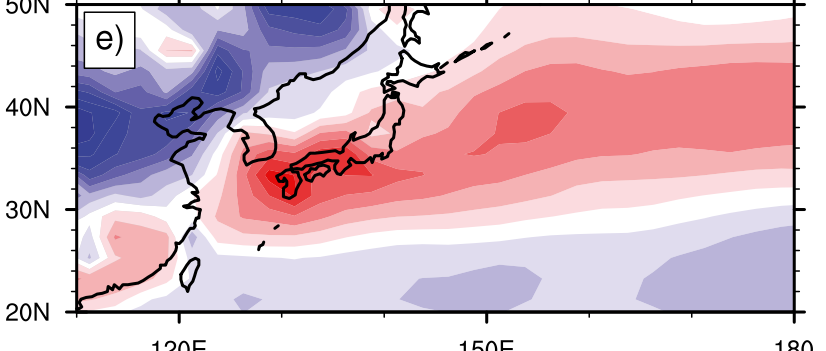

$120 \mathrm{E}$
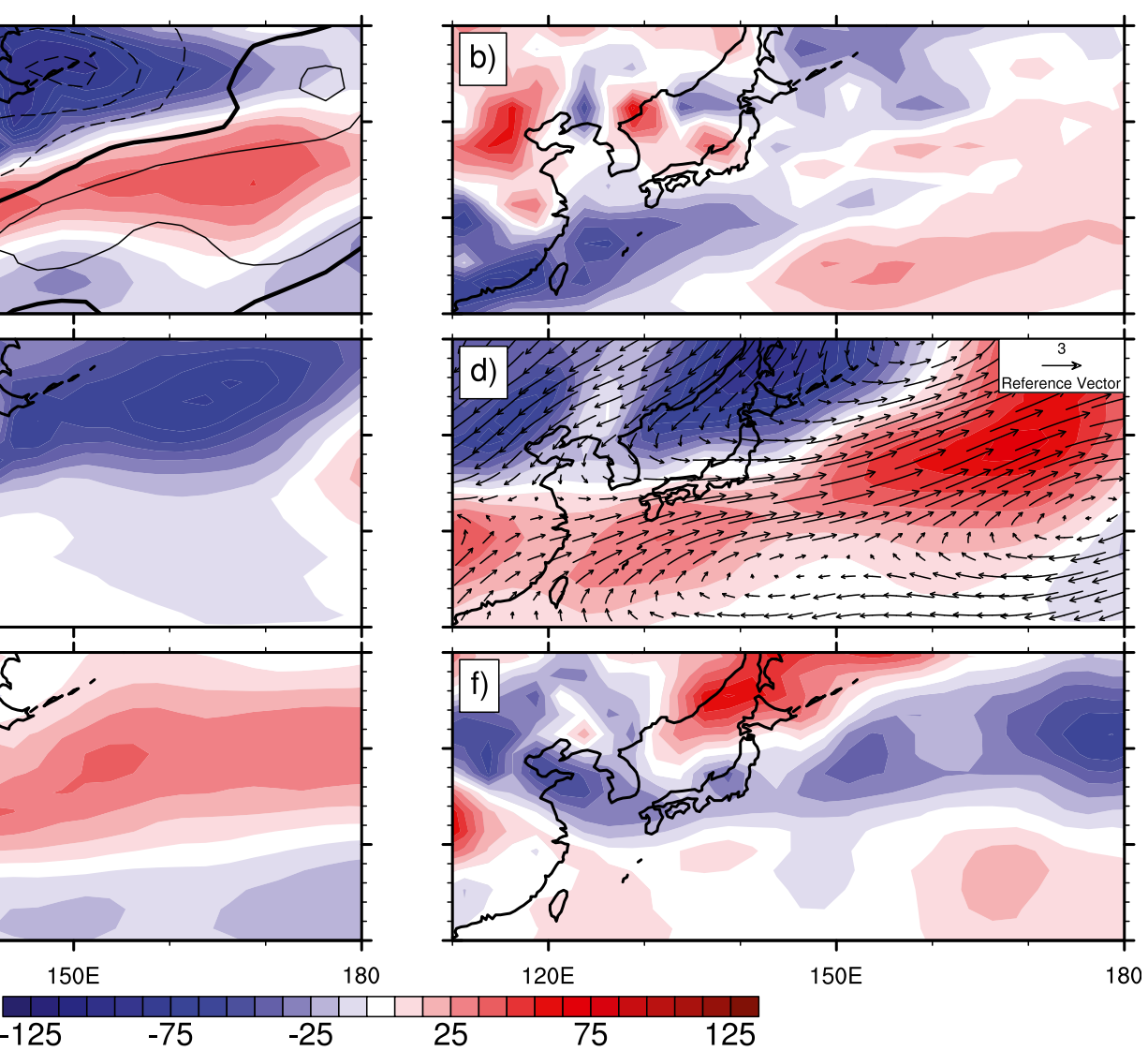

25

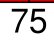

125

FIG. 11. Anomalies (TP - noTP experiments) in (a) horizontal dry enthalpy advection $-\left\langle\overline{c_{p} \mathbf{v} \cdot \nabla T}\right\rangle$ (color shading) and vertically integrated (normalized, not mass-weighted) meridional stationary eddy velocity divergence $\left\langle\overline{\partial_{y} v^{*}}\right\rangle$ (contours, interval $10^{-6} \mathrm{~s}^{-1}$ ), (b) latent energy advection $-\left\langle\overline{L_{v} \mathbf{v} \cdot \nabla q}\right\rangle$, (c) the advection of the stationary eddy dry enthalpy by the zonal-mean flow $-\left\langle c_{p}[\overline{\mathbf{v}}] \cdot \bar{\nabla} T^{*}\right\rangle,(\mathrm{d})$ the advection of the zonal-mean dry enthalpy by the stationary eddy velocity $-\left\langle c_{p} \overline{\mathbf{v}}^{*} \cdot[\overline{\mathbf{\nabla} T}]\right\rangle$ (color shading) and vertically integrated (normalized, not mass-weighted) stationary eddy wind fields (vectors) with reference vector $3 \mathrm{~m} \mathrm{~s}^{-1}$, (e) the advection of the stationary eddy energy by the stationary eddy velocity $-\left\langle c_{p} \overline{\mathbf{v}^{*}} \cdot \overline{\nabla T^{*}}\right\rangle$, and (f) the advection of the transient eddy energy by the transient eddy velocity $-\left\langle c_{p} \overline{\mathbf{v}^{\prime} \cdot \nabla T^{\prime}}\right\rangle$.

convergence (Fig. 14a) and partly offset by zonal wind divergence (Fig. 14b), resembles the anomaly in the product of the zonal mean moisture and stationary eddy convergence $\left\langle[\bar{q}] \overline{\nabla \cdot \mathbf{v}^{*}}\right\rangle$ (Fig. 12) because $\delta\left([\bar{q}] \overline{\nabla \cdot \mathbf{v}^{*}}\right)$ is highly weighted by $[\bar{q}]$.

At least qualitatively, the horizontal stationary eddy convergence and the meridional stationary eddy velocity can be related through Sverdrup balance, $\beta v^{*} \sim f \partial_{p} \omega^{*}$. While not perfect [note, for instance, that the maximum of the meridional stationary eddy velocity, indicated by the zero line of its meridional gradient (Fig. 14a), and the maximum southerly wind velocity are not exactly colocated], this balance does seem to hold reasonably well in the MB region.

\section{Summary and discussion}

We have used the MSE and moisture budgets in observations and simulations with and without the TP to identify large-scale mechanisms controlling the development and seasonality of the EASM. Novel results emerging from this study include the following:

- Positive horizontal moist enthalpy advection, and primarily dry enthalpy advection, sustains the MB rainfall band in a region of otherwise negative net energy input into the atmosphere.

- The zonal thermal gradient due to zonal asymmetries $\partial_{x} \overline{T^{*}}$ and the meridional stationary eddy velocity $\overline{v^{*}}$ are the dominant stationary terms creating the pattern of total dry enthalpy advection in the MB region.

- The largest contribution to the moisture flux convergence sustaining the MB rainfall arises from stationary eddy convergence $-\overline{\boldsymbol{\nabla} \cdot \mathbf{v}^{*}}$.

- The numerical experiments with and without the TP show that the TP primarily influences the formation of the MB front through changes in the meridional 


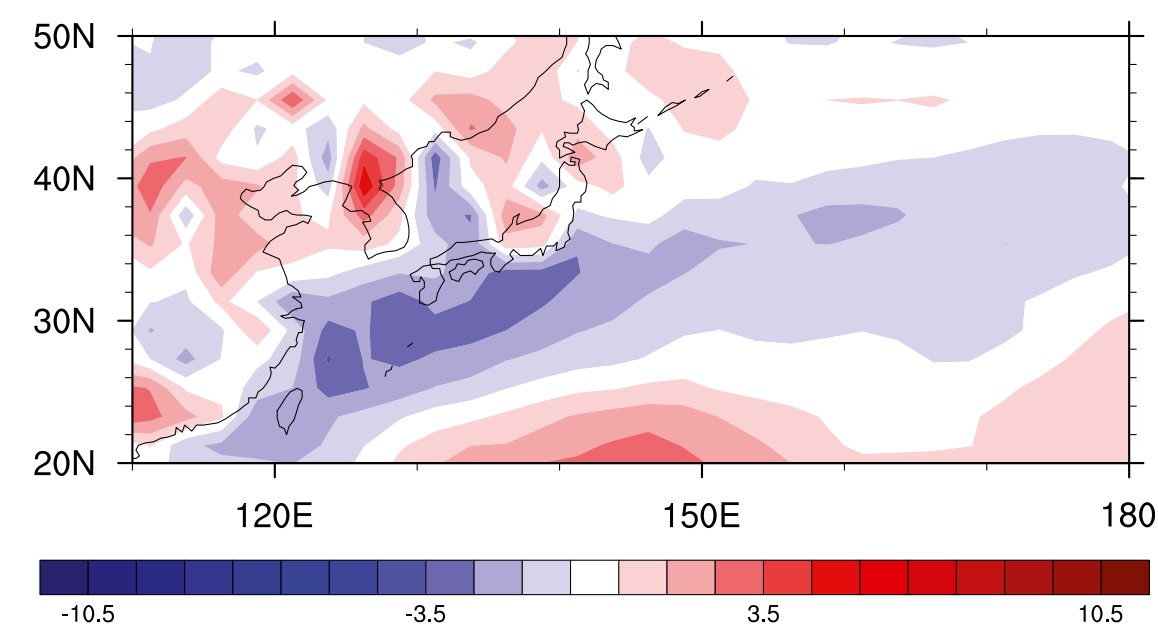

FIG. 12. Anomaly (TP - noTP experiments) in the product of the zonal mean moisture and stationary eddy divergence $\left\langle[\bar{q}] \overline{\nabla \cdot \mathbf{v}^{*}}\right\rangle$. (Color shading are in $\mathrm{mm} \mathrm{day}^{-1}$.)

stationary eddy velocity $\overline{v^{*}}$ as well as its meridional gradient $\partial_{y} \overline{v^{*}}$. Changes in the zonal thermal gradient due to zonal asymmetries $\partial_{x} T^{*}$ have a lesser impact and are confined to the near downstream of the TP.

In the literature, it is well accepted that the onset and demise of the MB season are governed by the position of the subtropical westerly jet (e.g., Ding and Chan 2005; Park et al. 2012; Molnar et al. 2010; Sampe and Xie 2010), but the exact mechanisms are less well agreed upon. It has been suggested in Sampe and Xie (2010) that horizontal warm air advection from the southeastern flank of the TP by the subtropical westerly jet can initiate ascending motion that would have to be balanced by lower-level convergence and can sustain the front even in the absence of diabatic forcing. Our analysis confirms the importance of the horizontal dry enthalpy advection, but in addition to the advection by the zonal mean flow of temperature zonal asymmetries, it exposes the meridional advection of the mean temperature by the meridional stationary eddy velocity as a key mechanism. It is revealing that in the AM2.1 simulations, the anomalous advection by $\overline{v^{*}}$ of the mean dry enthalpy is strongly coupled to the meridional stationary eddy velocity: increased meridional stationary eddy velocity amplifies the positive energy advection into the MB region and the northwestern Pacific Ocean and therefore intensifies the precipitation. Its pattern (i.e., latitudinal gradient) determines the wind convergence and is closely coupled with zonal eddy velocity. Although the total (zonal and meridional) warm air advection, as investigated by Sampe and Xie (2010), can successfully explain the location and seasonality of the MB, the application of the MSE budget, together with the eddy decomposition, allows us to isolate one single dominant factor $\overline{v^{*}}$ based on a widely applicable theoretical framework, which might encapsulate the influences of the TP on the formation of the EASM.

Together with the upper-level westerly jet, the lowerlevel southerly flow around the subtropical high has also been identified as important in the climatological position and seasonal evolution of the MB front. Rodwell and Hoskins (2001) investigated the dynamics of summertime subtropical anticyclones in a dry model forced by the observed diabatic heating and argued for a more dominant role of the diabatic heating over the topography in driving the meridional southerly flow in the western flank of the North Pacific subtropical anticyclone. In moist circulations, such as the MB front, however, this separation might be artificial, given that patterns of convergence and divergence induced by topography shape and interact with the distribution of the diabatic heating. By using the MSE budget, we circumvent the need to specify or diagnose the diabatic heating and more generally focus on the role of thermally and/or mechanically induced stationary flows on the formation of the MB front. Kodama (1992) investigated the baiu front from an observational perspective, together with other subtropical convergence zones (STCZs), and found that the lower-level poleward flow around the subtropical high and the subtropical jet are two necessary circulation features for generating the STCZs. His study highlights the role of the lower-level poleward flow in water vapor transport, intensification of the moisture convergence, frontogenesis in equivalent potential temperature fields, and generation of convective instability. The poleward flow itself is interpreted as 

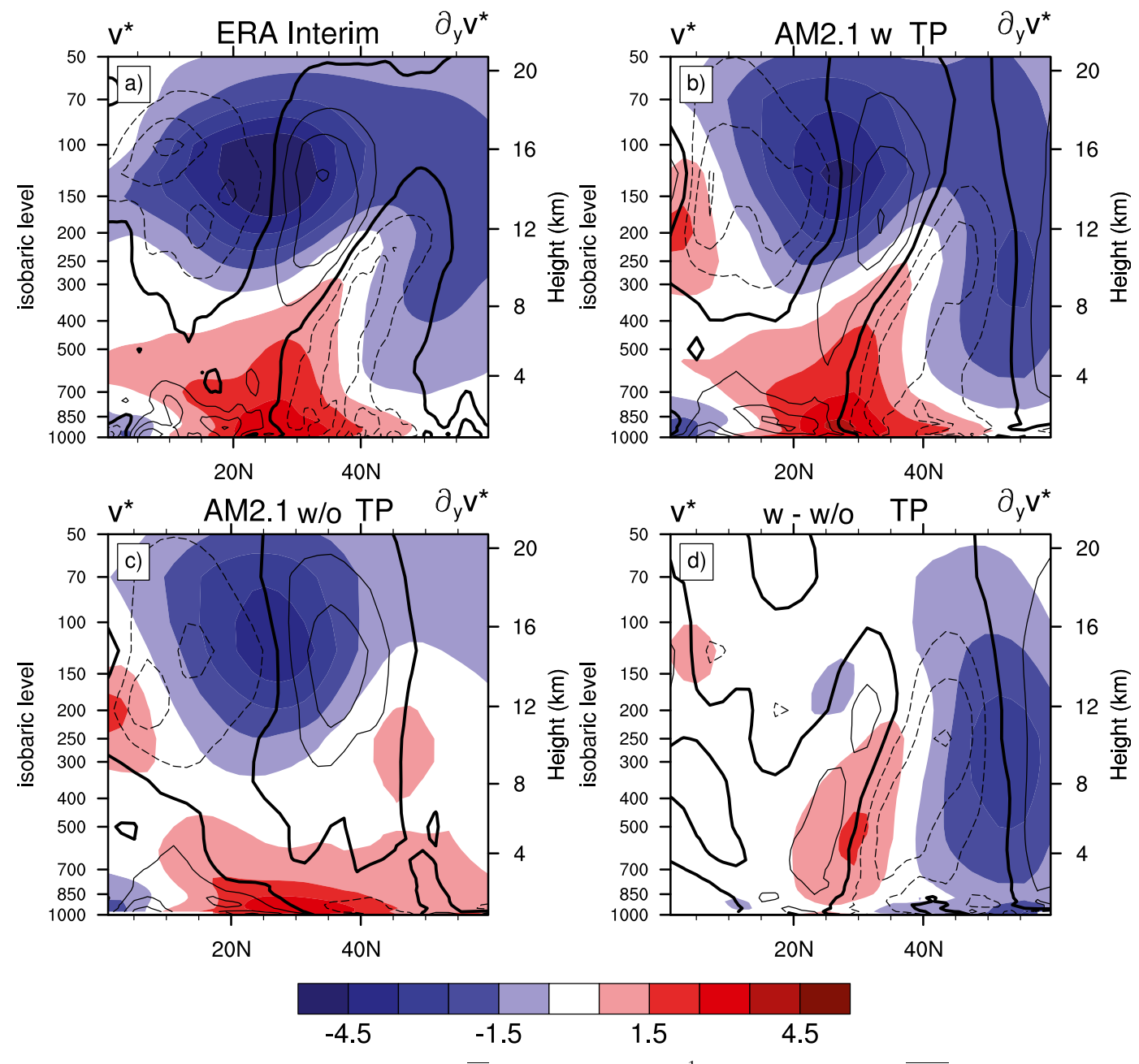

FIG. 13. Meridional stationary eddy velocity $\overline{v^{*}}$ (color shading; $\mathrm{m} \mathrm{s}^{-1}$ ) and its convergence $\overline{\partial_{y} v^{*}}$ (contours, interval $10^{-6} \mathrm{~s}^{-1}$ ) averaged from $110^{\circ}$ to $160^{\circ} \mathrm{E}$ in (a) the ERA-Interim reanalysis data and in the AM2.1 simulation in the (b) presence and (c) absence of the TP, and (d) the difference between (a) and (b).

forming geostrophically in the longitudinal pressure gradient between the monsoonal heat low and the subtropical high (Kodama 1992; Ninomiya 1984). Our analysis suggests that these circulation features might not be independent from each other, and, by means of the MSE and moisture budgets, sheds further light into their role in the MB front in terms of their resulting pattern of positive enthalpy advection. In fact, in the presence of upper tropospheric westerly flow, any zonal asymmetry, such as topography, land-sea thermal contrast, and diabatic heating, can induce stationary Rossby waves, with associated temperature, moisture, and wind perturbations [see, e.g., Held et al. (2002) for a comprehensive review of stationary waves in the Northern Hemisphere winter]. Dispersion characteristics of these stationary Rossby waves might explain aspects of the observed MB, such as its spatial extent and tilted structure. These questions will be addressed in future work.

The results presented here suggest that the TP might influence the EASM by both thermal and mechanical effects. In nature, these two effects cannot be separated and we do not attempt to give a quantitative assessment of their relative roles in this paper. Future studies will attempt a more quantitative assessment by performing modified surface flux and albedo simulations (e.g., $\mathrm{Wu}$ et al. 2012). However, the successful explanation of the MB rainfall season within the framework of the MSE budget gives us confidence in continuing to explore attributable factors in the intermodel spread in phase 5 of the Coupled Model Intercomparison Project (CMIP5) EASM simulations and in attempting to assess future changes in the EASM in the context of global warming. Factors including accelerating warming and widespread 

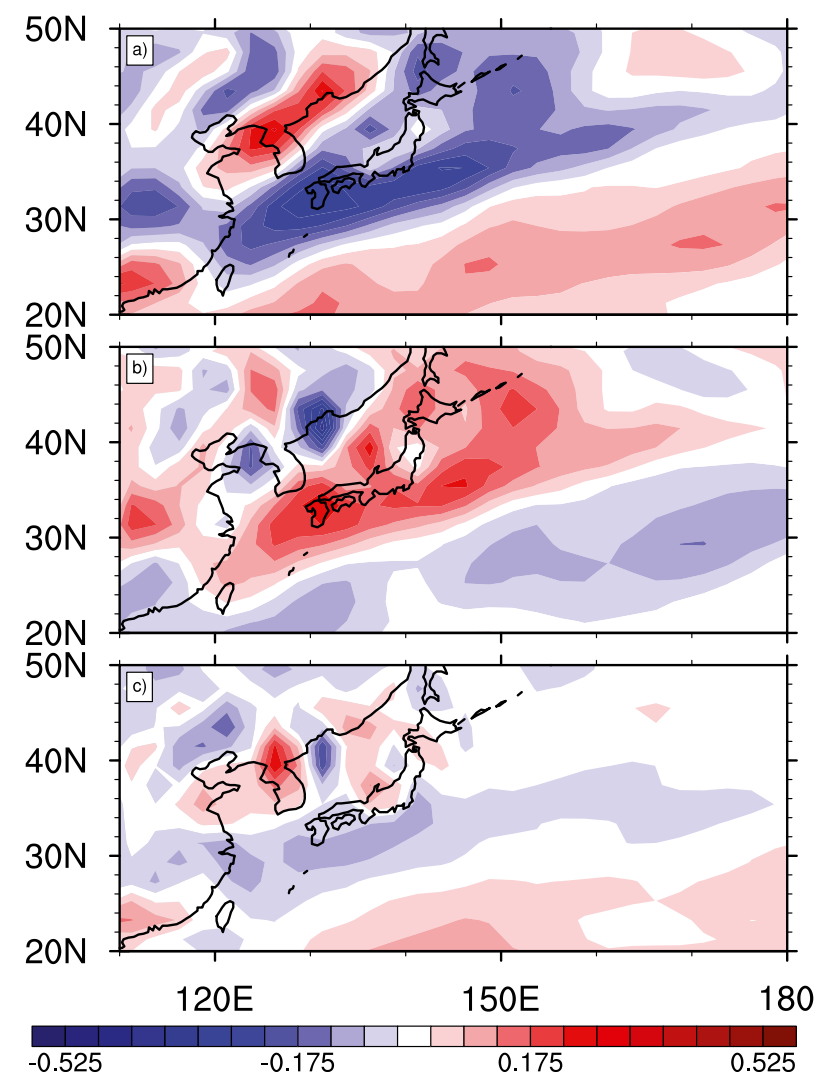

FIG. 14. Anomalies (TP - noTP experiments) in (a) $\partial_{y} \overline{v^{*}}$, (b) $\partial_{x} \overline{u^{*}}$, zonal component of the wind and (c) $\nabla \cdot \overline{\mathbf{v}^{*}}$ integrated (normalized, not mass-weighted) from the surface to $700 \mathrm{hPa}$. (Color shading is in day $^{-1}$.)

loss of glacier and snow cover throughout the twenty-first century in the Special Report on Emissions Scenarios (SRES) A1B scenario (Solomon et al. 2007), the expansion of the subtropical dry zones and changes in position and strength of the westerly jet, the possible nonlinear changes in dry enthalpy advection and latent energy advection because of polar amplification, and heterogeneous changes in relative humidity might all be critical in the future evolution of the EASM. The MSE and moisture budgets are expected to provide insights into the possible role of all these factors in EASM changes in a unified theoretical framework.

Acknowledgments. We thank Hyo-Seok Park for the AM2.1 model setup and several conversations, Tim Merlis and David Neelin for helpful discussions, and three anonymous reviewers, whose insightful comments helped improve the manuscript. We use the NCAR Command Language (version 6.1.2; http://dx.doi.org/ 10.5065/D6WD3XH5) to create the plots and analyze the data. The data analyses and simulations were conducted on the Caltech's Division of Geological and Planetary Sciences high-performance computing cluster.

\section{REFERENCES}

Abe, M., T. Yasunari, and A. Kitoh, 2004: Effects of large-scale orography on the coupled atmosphere-ocean system in the tropical Indian and Pacific Oceans in boreal summer. J. Meteor. Soc. Japan, 82, 745-759, doi:10.2151/ jmsj.2004.745.

Anderson, J., and Coauthors, 2004: The new GFDL global atmosphere and land model AM2-LM2: Evaluation with prescribed SST simulations. J. Climate, 17, 4641-4673, doi:10.1175/ JCLI-3223.1.

Berrisford, P., P. Kållberg, S. Kobayashi, D. Dee, S. Uppala, A. Simmons, P. Poli, and H. Sato, 2011: Atmospheric conservation properties in ERA-Interim. Quart. J. Roy. Meteor. Soc., 137, 1381-1399, doi:10.1002/qj.864.

Chen, T., and C. Chang, 1980: The structure and vorticity budget of an early summer monsoon trough (meiyu) over southeastern China and Japan. Mon. Wea. Rev., 108, 942-953, doi:10.1175/ 1520-0493(1980)108<0942:TSAVBO > 2.0.CO;2.

Chou, C., and J. Neelin, 2003: Mechanisms limiting the northward extent of the northern summer monsoons over North America, Asia, and Africa. J. Climate, 16, 406-425, doi:10.1175/ 1520-0442(2003)016<0406:MLTNEO > 2.0.CO;2.

$\longrightarrow,-$, and H. Su, 2001: Ocean-atmosphere-land feedbacks in an idealized monsoon. Quart. J. Roy. Meteor. Soc., 127, 1869 1891, doi:10.1002/qj.49712757602.

Dao, S., and L. Chen, 1957: The structure of general circulation over the continent of Asia in summer. J. Meteor. Soc. Japan, 35, 215-229.

Dee, D., and Coauthors, 2011: The ERA-Interim reanalysis: Configuration and performance of the data assimilation system. Quart. J. Roy. Meteor. Soc., 137, 553-597, doi:10.1002/qj.828.

Dima, I., and J. M. Wallace, 2003: On the seasonality of the Hadley cell. J. Atmos. Sci., 60, 1522-1527, doi:10.1175/1520-0469 (2003) $060<1522:$ OTSOTH $>2.0 . \mathrm{CO} ; 2$.

Ding, Y., 1992: Summer monsoon rainfalls in China. J. Meteor. Soc. Japan, 70, 373-396.

— , and J. Chan, 2005: The East Asian summer monsoon: An overview. Meteor. Atmos. Phys., 89, 117-142, doi:10.1007/ s00703-005-0125-z.

Enomoto, T., B. J. Hoskins, and Y. Matsuda, 2003: The formation mechanism of the Bonin high in August. Quart. J. Roy. Meteor. Soc., 129, 157-178, doi:10.1256/qj.01.211.

Flohn, H., 1957: Large-scale aspects of the "summer monsoon" in South and East Asia. J. Meteor. Soc. Japan, 75, 180-186.

Gao, H., and S. Yang, 2009: A severe drought event in northern China in winter 2008-2009 and the possible influences of La Niña and Tibetan Plateau. J. Geophys. Res., 114, D24104, doi:10.1029/2009JD012430.

,-- A. Kumar, Z. Hu, B. Huang, Y. Li, and B. Jha, 2011: Variations of the East Asian meiyu and simulation and prediction by the NCEP climate forecast system. J. Climate, 24, 94-108, doi:10.1175/2010JCLI3540.1.

Held, I. M., M. Ting, and H. Wang, 2002: Northern winter stationary waves: Theory and modeling. J. Climate, 15, 2125-2144, doi:10.1175/1520-0442(2002)015<2125:NWSWTA > 2.0.CO;2.

Hirahara, S., H. Ohno, Y. Oikawa, and S. Maeda, 2012: Strengthening of the southern side of the jet stream and delayed withdrawal of Baiu season in future climate. J. Meteor. Soc. Japan, 90, 663-671. 
Hsu, P., T. Li, H. Murakami, and A. Kitoh, 2013: Future change of the global monsoon revealed from 19 CMIP5 models. J. Geophys. Res., 18, 1247-1260, doi:10.1002/jgrd.50145.

Huffman, G., R. Adler, M. Morrissey, D. Bolvin, S. Curtis, R. Joyce, B. McGavock, and J. Susskind, 2001: Global precipitation at one-degree daily resolution from multisatellite observations. J. Hydrometeor., 2, 36-50, doi:10.1175/ 1525-7541(2001)002<0036:GPAODD $>2.0 . \mathrm{CO} ; 2$.

Kaspi, Y., and T. Schneider, 2013: The role of stationary eddies in shaping midlatitude storm tracks. J. Atmos. Sci., 70, 25962613, doi:10.1175/JAS-D-12-082.1.

Kitoh, A., 2004: Effects of mountain uplift on East Asian summer climate investigated by a coupled atmosphere-ocean GCM J. Climate, 17, 783-802, doi:10.1175/1520-0442(2004)017<0783: EOMUOE $>2.0 . \mathrm{CO} ; 2$.

Kodama, Y.-M., 1992: Large-scale common features of subtropical precipitation zones (the Baiu frontal zone, the SPCZ and the SACZ). Part I: Characteristics of subtropical frontal zones. J. Meteor. Soc. Japan, 70, 813-836.

Krishnan, R., S. Sundaram, P. Swapna, V. Kumar, D. Ayantika, and M. Mujumdar, 2011: The crucial role of ocean-atmosphere coupling on the Indian monsoon anomalous response during dipole events. Climate Dyn., 37, 1-17, doi:10.1007/ s00382-010-0830-2.

Kuo, Y.-H., L. Cheng, and R. A. Anthes, 1986: Mesoscale analyses of the Sichuan flood catastrophe, 11-15 July 1981. Mon. Wea. Rev., 114, 1984-2003, doi:10.1175/1520-0493(1986)114<1984: MAOTSF $>2.0 . C O ; 2$.

Li, C., and M. Yanai, 1996: The onset and interannual variability of the Asian summer monsoon in relation to landsea thermal contrast. J. Climate, 9, 358-375, doi:10.1175/ 1520-0442(1996)009<0358:TOAIVO > 2.0.CO;2.

Lin, S.-J., 2004: A "vertically Lagrangian" finite-volume dynamical core for global models. Mon. Wea. Rev., 132, 2293-2307, doi:10.1175/1520-0493(2004)132<2293: AVLFDC $>2.0 . C O ; 2$.

Liu, X., and Z.-Y. Yin, 2002: Sensitivity of East Asian monsoon climate to the uplift of the Tibetan Plateau. Palaeogeogr. Palaeoclimatol. Palaeoecol., 183, 223-245, doi:10.1016/ S0031-0182(01)00488-6.

Merlis, T. M., and T. Schneider, 2010: Atmospheric dynamics of Earth-like tidally locked aquaplanets. J. Adv. Model. Earth Syst., 2 (13), doi:10.3894/JAMES.2010.2.13.

Molnar, P., W. Boos, and D. Battisti, 2010: Orographic controls on climate and paleoclimate of Asia: Thermal and mechanical roles for the Tibetan Plateau. Annu. Rev. Earth Planet. Sci., 38, 77-102, doi:10.1146/annurev-earth-040809-152456.

Neelin, J., 2007: Moist dynamics of tropical convection zones in monsoons, teleconnections, and global warming. The Global Circulation of the Atmosphere, T. Schneider and A. H. Sobel, Eds., Princeton University Press, 267-301.

Ninomiya, K., 1984: Characteristics of Baiu front as a predominant subtropical front in the summer Northern Hemisphere. J. Meteor. Soc. Japan, 62, 880-894.

_- , and T. Murakami, 1987: The early summer rainy season (Baiu) over Japan. Monsoon Meteorology, C.-P. Chang and T. N. Krishnamurti, Eds., Oxford University Press, 93-121.

Park, H., J. Chiang, and S. Bordoni, 2012: Mechanical impact of the Tibetan Plateau on the seasonal evolution of the South Asian monsoon. J. Climate, 25, 2394-2407, doi:10.1175/ JCLI-D-11-00281.1.

Peixoto, J. P., and A. H. Oort, 1992: Physics of Climate. American Institute of Physics, 520 pp.
Rodwell, M., and B. Hoskins, 1996: Monsoons and the dynamics of deserts. Quart. J. Roy. Meteor. Soc., 122, 1385-1404, doi:10.1002/qj.49712253408.

—, and —-, 2001: Subtropical anticyclones and summer monsoons. J. Climate, 14, 3192-3211, doi:10.1175/ 1520-0442(2001)014<3192:SAASM >2.0.CO;2.

Saito, N., 1985: Quasi-stationary waves in mid-latitudes and the Baiu in Japan. J. Meteor. Soc. Japan, 63, 983-995.

Sampe, T., and S. Xie, 2010: Large-scale dynamics of the MeiyuBaiu rainband: Environmental forcing by the westerly jet. J. Climate, 23, 113-134, doi:10.1175/2009JCLI3128.1.

Schiemann, R., D. Lüthi, and C. Schär, 2009: Seasonality and interannual variability of the westerly jet in the Tibetan Plateau region. J. Climate, 22, 2940-2957, doi:10.1175/ 2008JCLI2625.1.

Schneider, T., 2004: The tropopause and the thermal stratification in the extratropics of a dry atmosphere. J. Atmos. Sci., 61, 1317-1340, doi:10.1175/1520-0469(2004)061<1317: TTATTS $>2.0 . \mathrm{CO} ; 2$.

Smith, T. M., R. W. Reynolds, R. E. Livezey, and D. C. Stokes, 1996: Reconstruction of historical sea surface temperatures using empirical orthogonal functions. J. Climate, 9, 1403-1420, doi:10.1175/1520-0442(1996)009<1403:ROHSST >2.0.CO;2.

Sobel, A., J. Nilsson, and L. M. Polvani, 2001: The weak temperature gradient approximation and balanced tropical moisture waves. J. Atmos. Sci., 58, 3650-3665, doi:10.1175/1520-0469 (2001) $058<3650$ :TWTGAA $>2.0$. CO 2 .

Solomon, S., D. Qin, M. Manning, Z. Chen, M. Marquis, K. Averyt, M. M. B. Tignor, and H. L. Miller Jr., 2007: Climate Change 2007: The Physical Science Basis. Cambridge University Press, 996 pp.

Suda, K., and T. Asakura, 1955: A study on the unusual "Baiu" season in 1954 by means of Northern Hemisphere upper air mean charts. J. Meteor. Soc. Japan, 33, 1-12.

Tao, S., 1987: A review of recent research on the East Asian summer monsoon in China. Monsoon Meteorology, C. P. Chang and T. N. Krishnamurti, Eds., Oxford University Press, 60-92.

Trenberth, K. E., J. W. Hurrell, and D. P. Stepaniak, 2006: The Asian monsoon: Global perspectives. The Asian Monsoon, B. Wang, Ed., Springer Praxis, 67-87.

Waliser, D. E., 2006: Intraseasonal variability. The Asian Monsoon, B. Wang, Ed., Springer Praxis, 203-257.

Wang, B., 1987: The development mechanism for Tibetan Plateau warm vortices. J. Atmos. Sci., 44, 2978-2994, doi:10.1175/ 1520-0469(1987)044<2978:TDMFTP>2.0.CO;2.

_ 2006: The Asian Monsoon. Springer Praxis, 787 pp.

Wang, W., Y.-H. Kuo, and T. T. Warner, 1993: A diabatically driven mesoscale vortex in the lee of the Tibetan Plateau. Mon. Wea. Rev., 121, 2542-2561, doi:10.1175/1520-0493(1993)121<2542: ADDMVI $>2.0 . \mathrm{CO} ; 2$.

Webster, P., 1987: The elementary monsoon. Monsoons, J. S. Fein and P. L. Stephens, Eds., John Wiley and Sons, 3-32.

, and J. Fasullo, 2003: Monsoon: Dynamical theory. Encyclopedia of Atmospheric Sciences, Vol. 3, Academic Press, 1370 1391.

Wu, G., W. Li, H. Guo, H. Liu, J. Xue, and Z. Wang, 1997: Sensible heat driven air-pump over the Tibetan Plateau and its impacts on the Asian summer monsoon. Collections in the Memory of Zhao Jiuzhang, Y. Duzheng, Ed., Chinese Science Press, 116126.

, L. Sun, Y. Liu, H. Liu, S. Sun, and W. Li, 2002: Impacts of land surface processes on summer climate. Selected Papers of 
the Fourth Conference on East Asia and Western Pacific Meteorology and Climate, C. P. Chang et al., Eds., World Scientific, 64-76.

, and Coauthors, 2007: The influence of mechanical and thermal forcing by the Tibetan Plateau on Asian climate. J. Hydrometeor., 8, 770-789, doi:10.1175/JHM609.1.

-, Y. Liu, B. He, Q. Bao, A. Duan, and F. Jin, 2012: Thermal controls on the Asian summer monsoon. Sci. Rep., 2, 404, doi:10.1038/srep00404.
Yanai, M., and G. Wu, 2006: Effects of the Tibetan Plateau. The Asian Monsoon, B. Wang, Ed., Springer Praxis, 513-549.

Yang, S., and W. K.-M. Lau, 2006: Interannual variability of the Asian monsoon. The Asian Monsoon, B. Wang, Ed., Springer Praxis, 259-293.

Yeh, T. C., S. W. Lo, and E. C. Chu, 1957: On the heat balance and circulation structure in the troposphere over the Tibetan Plateau and its vicinity. Acta Meteor. Sin., 28, 108-121. 